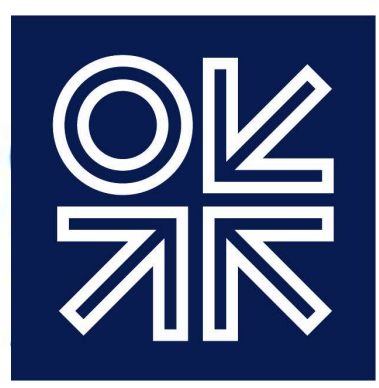

THE OXFORD INSTITUTE

FOR ENERGY STUDIES

June 2018

\title{
Egypt - a return to a balanced gas market?
}

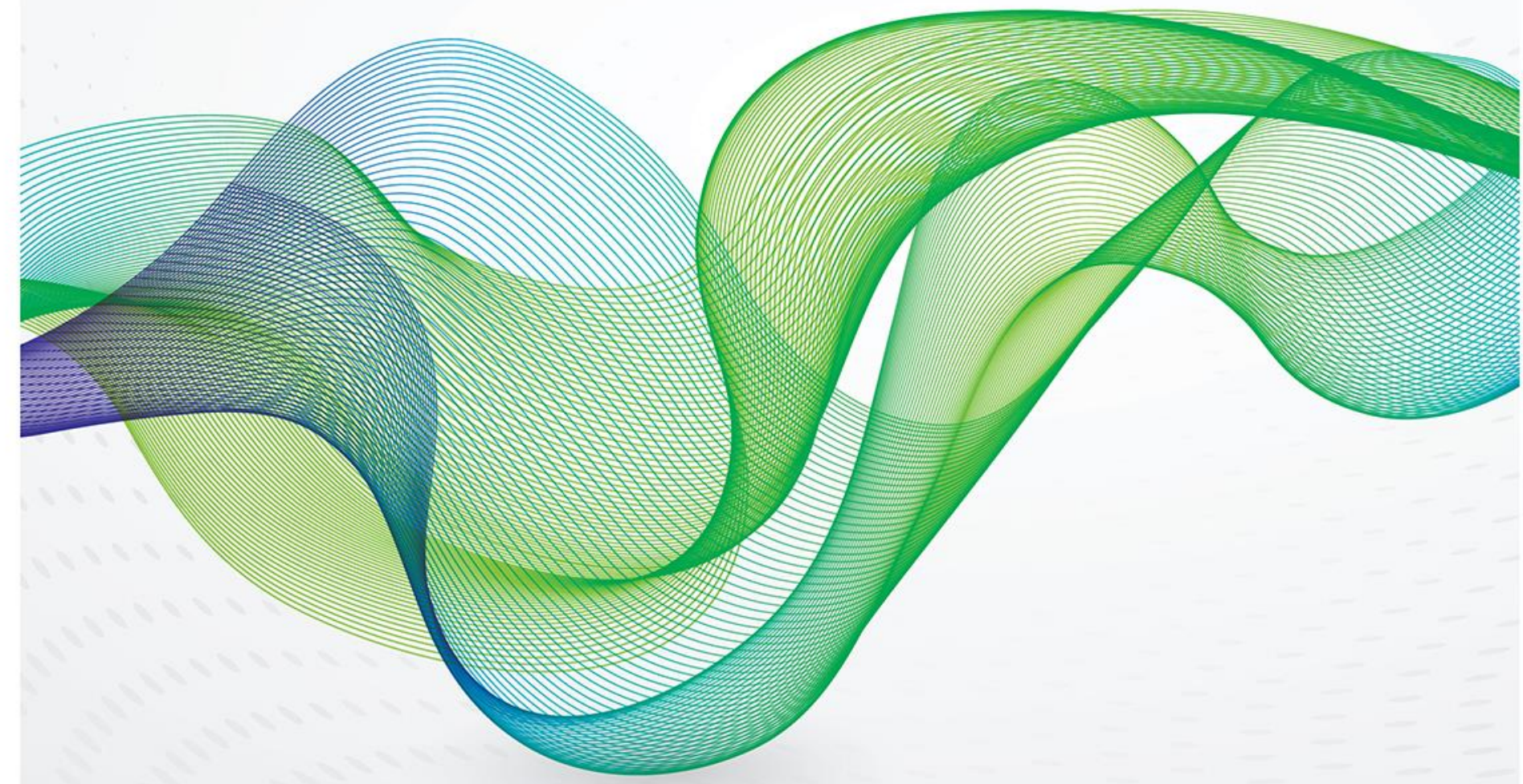



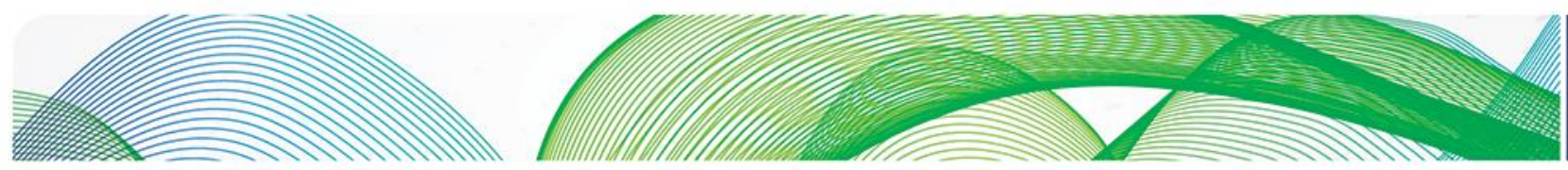

\section{잊조}

The contents of this paper are the author's sole responsibility. They do not necessarily represent the views of the Oxford Institute for Energy Studies or any of its members.

Copyright @ 2018

Oxford Institute for Energy Studies

(Registered Charity, No. 286084)

This publication may be reproduced in part for educational or non-profit purposes without special permission from the copyright holder, provided acknowledgment of the source is made. No use of this publication may be made for resale or for any other commercial purpose whatsoever without prior permission in writing from the Oxford Institute for Energy Studies.

ISBN 978-1-78467-112-9

DOI: https://doi.org/10.26889/9781784671129 

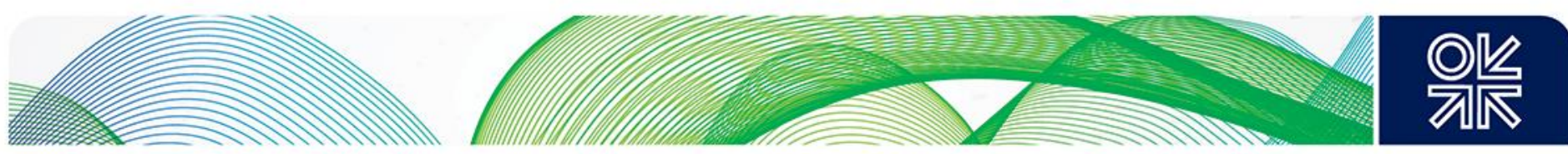

\section{Preface}

When Egypt became an importer of gas in 2015 it was a shock to the global gas market, as although the political and economic problems in the country were clear, it was nevertheless a surprise when surging gas demand overtook stagnant indigenous production. As with so many countries in the MENA region, the key problem has been low subsidised gas prices that have encouraged rapid demand growth, and in this paper Mostefa Ouki takes a close look at gas demand across the Egyptian economy and concludes that it will continue to grow, despite the best efforts of the government to reform the domestic gas market. It would seem that the best they can hope for is slow demand growth, but this may be enough to return the Egyptian gas market to balance thanks to new policies to encourage upstream development. The author describes in detail the steps put into place that have led, amongst other successes, to the discovery of the giant Zohr field and to a number of other important new finds which will transform Egypt's gas supply and demand balance over the next few years.

However, although this change should allow Egypt to end gas imports in the next year or so, and could even see exports re-commence, the real significance of this paper for the global gas market is the question of how long this new situation can last. Ouki highlights a number of domestic reform issues which need to be addressed if the balance of the Egyptian gas market is to be maintained, and he points out that there is a significant risk that the country could easily slip back to becoming an importer again if the government does not address a complex set of issues in the reform process, not the least of which will be the unwinding of subsidies. Egypt has the resources to be at least selfsufficient in gas if it can address demand side issues in its economy and has the infrastructure available to become an LNG hub for the East Mediterranean region if it can optimise its sources of supply. Its success or failure in these endeavours can have an important bearing on the balance of the European and global gas markets, and this paper makes a key contribution to the understanding of this vital topic.

\section{James Henderson}

Director, Natural Gas Programme

Oxford Institute for Energy Studies 

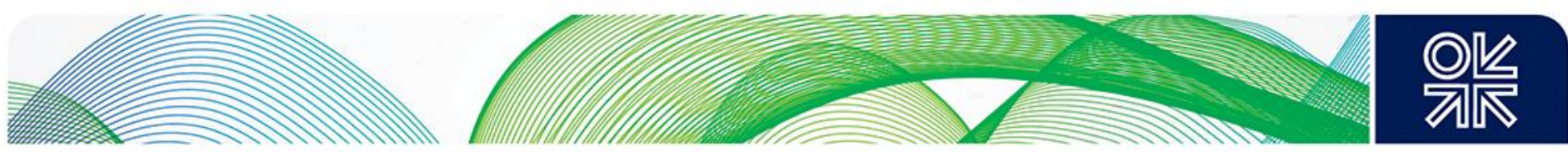

\section{Acknowledgements}

The author wishes to present his grateful thanks to James Henderson, Ali Aissaoui, Anastasios Giamouridis, and anonymous reviewers from the energy industry for their kind assistance and insightful and valuable comments. 

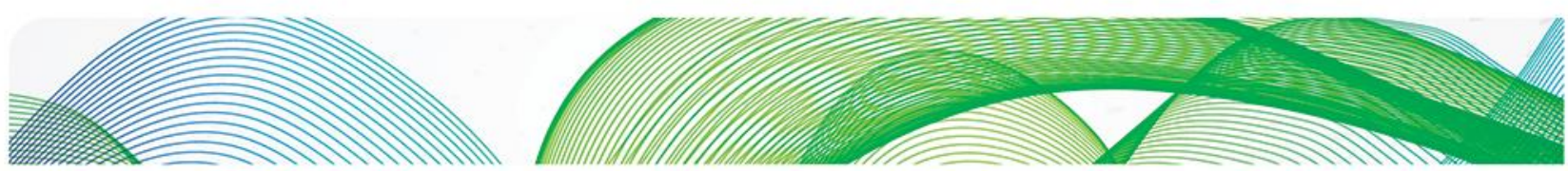

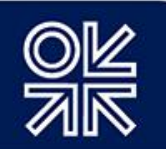

\section{Contents}

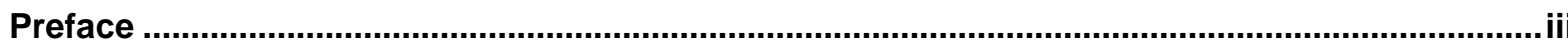

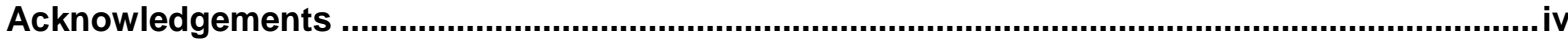

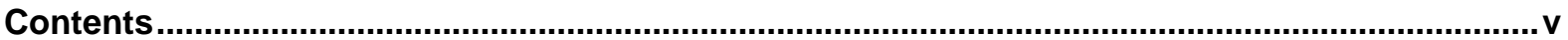

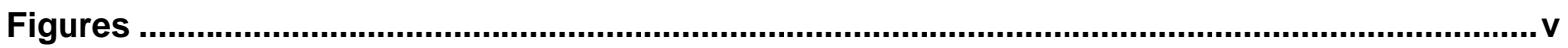

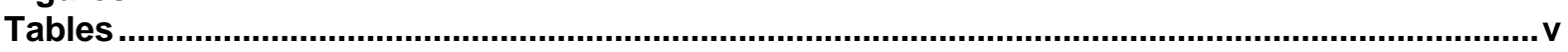

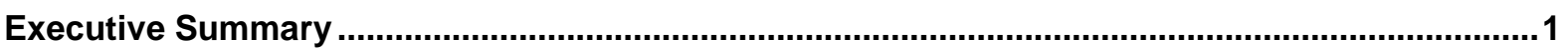

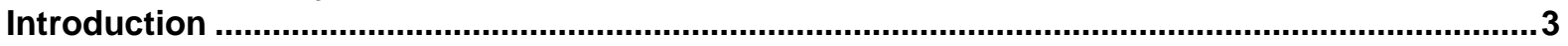

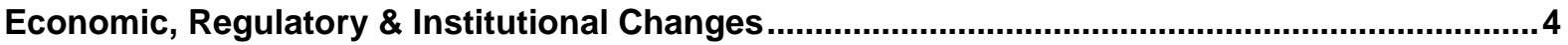

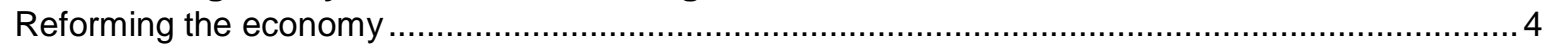

Energy strategy \& petroleum sector modernisation programme .................................................. 5

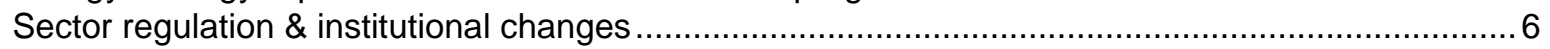

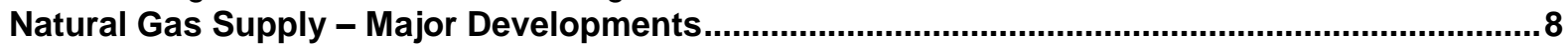

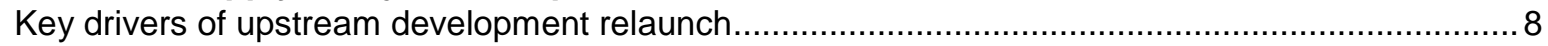

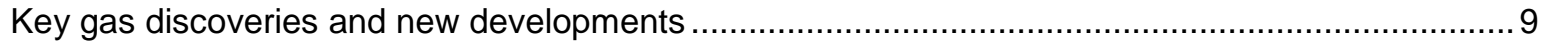

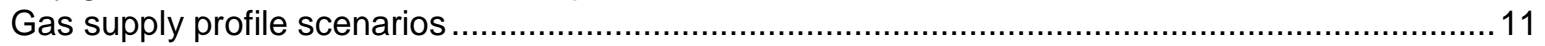

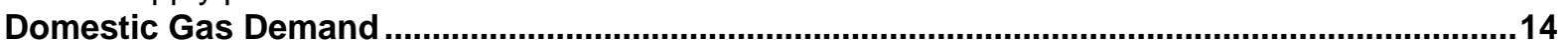

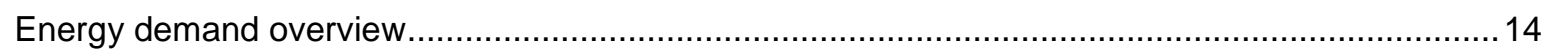

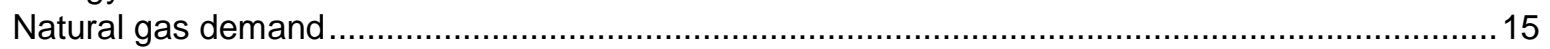

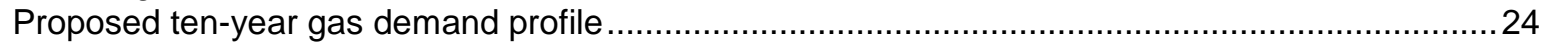

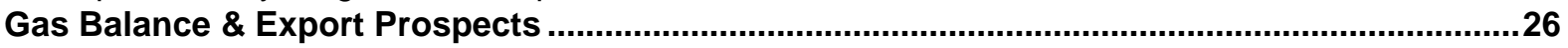

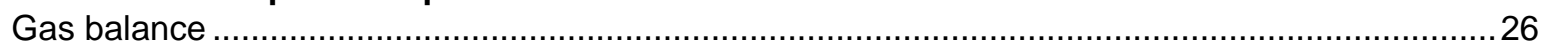

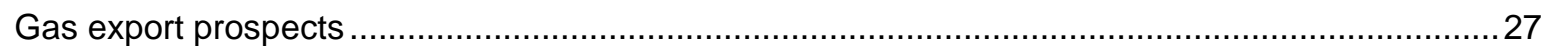

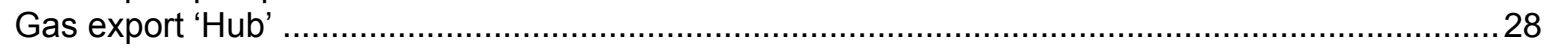

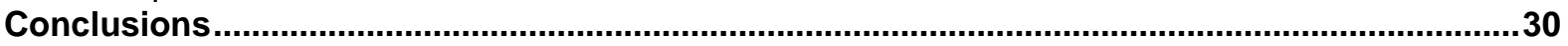

\section{Figures}

Figure 1: Egypt Gas Supply Profile - Scenario A (Bcf/d, averages) ….............................................12

Figure 2: Egypt Gas Supply Profile - Scenario B (Bcf/d, averages) ..........................................13

Figure 3: Egypt's Primary Energy Supply (2015) ................................................................... 14

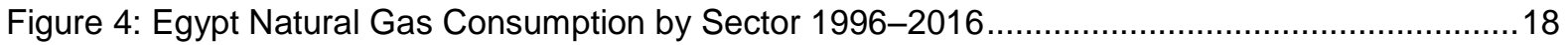

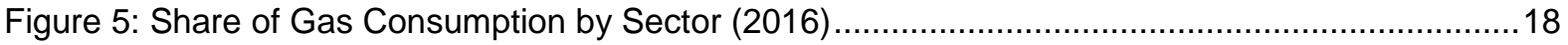

Figure 6: Egypt Total Electricity Sold by Category (2015/2016) …….......................................2

Figure 7: Proposed ten-year gas demand profile (Bcfd, averages) ...............................................25

Figure 8: Gas balance - supply scenario A (Bcfd, averages) .....................................................26

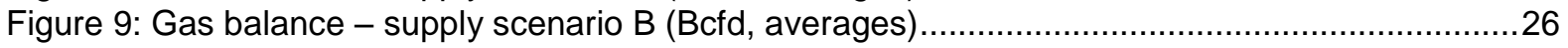

\section{Tables}

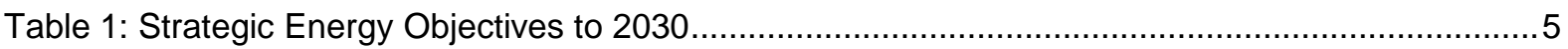

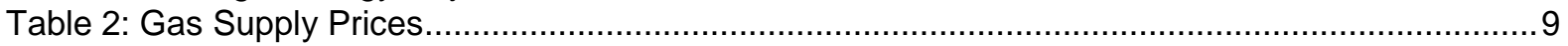

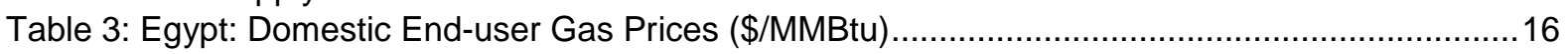



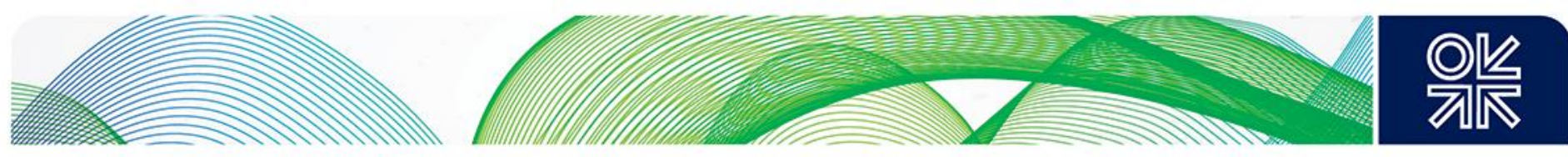

\section{Executive Summary}

Egypt is the second largest African economy and one of the largest economies in the Middle East and North Africa (MENA) region. It is also one of the biggest energy markets in the Africa and MENA regions with a relatively extensive energy infrastructure, especially for natural gas. In 2015, Egypt became a net gas importer after being a key North African gas exporter for a period of ten years. This unfortunate, but not unexpected, situation was the result of a decline in Egypt's indigenous natural gas production combined with a rapidly rising domestic gas demand driven mainly by large energy price subsidies.

Major changes are presently taking place on the gas supply side which are significantly impacting on the country's natural gas balance and the economy in general. Given the dominant position of natural gas in Egypt's energy scene, the government needed to take urgent and drastic action to unlock Egypt's gas supply potential. In 2013/2014, it started implementing a more favourable upstream development policy to reverse the country's declining gas supply profile. New policy measures helped bring about the discovery of the Zohr field in 2015 and its fast-track development, and other gas discoveries (West Nile Delta, Greater Nooros, and Atoll) were made in recent years. Future supplies from all the newly discovered fields are expected to produce the equivalent of Egypt's present natural gas output.

On the gas demand side, Egypt is still facing the same structural difficulties. The financially constrained power sector continues to account for about two thirds of total domestic gas use. The other large gas users (industry), however, are now facing commercial challenges under the current higher gas price regime that will affect their gas demand. Among the key drivers of gas demand growth, in addition to economic growth prospects, are; the future movement of domestic gas prices, especially for the power sector, and adequate availability of natural gas infrastructure capacity to meet existing and potential expansion of gas demand in new areas/regions. Alternative energy sources for electricity generation are expected to take longer than ten years to have a significant effect on the reduction of gas-fired generation and, therefore, on the total gas demand. Overall, the review of gas demand by sector of use shows that Egypt's natural gas demand will continue to grow, but at a slower pace compared to the last two decades' growth rate.

A new gas market law and its executive regulations were issued in August 2017 and February 2018, respectively, to reform Egypt's domestic gas market. The full implementation and the liberalization of the market will take a long time to achieve, but this new gas law is an important positive step forward. However, several important implementation issues remain to be clarified. It is expected that the new executive regulations and related new rules and directives that will be issued by the new gas market regulatory authority will address such issues.

Meeting the needs of the domestic gas market is one of the key objectives and priorities of the Egyptian government. Drawing on presently available public data and information, this target is about to be achieved and a balanced market could possibly be sustained until at least the early 2020s. Egypt will also resume natural gas exports, but it is unlikely to regain its past natural gas export position. The export window could last far less than ten years and export levels could decline quickly, again this is based on publicly available supply and demand data and information.

Nevertheless, there are key policy questions that need to be addressed. How will the government wish to continue to monetize its gas resources? Subject to existing contractual gas export commitments, should the state capture additional rent through further domestic gas monetization (gas use in petrochemicals and industries) or mainly through exports or a through a combination of the two? Under a commercially viable domestic energy pricing structure, such questions would be easier to address. However, it is difficult to justify the continuation of energy price subsidies to domestic gas monetization projects both economically and financially. 

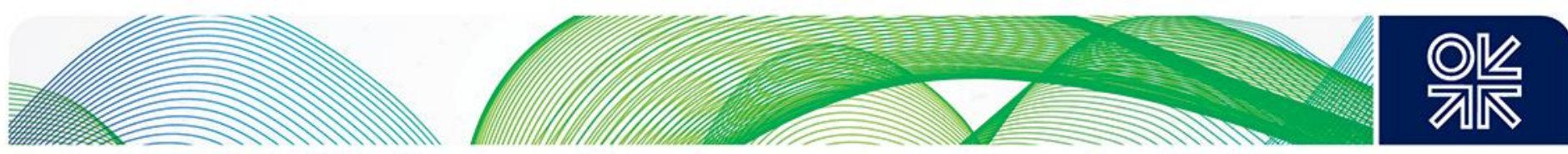

There is a need to focus not only on the yet-to-find gas resources to prove up additional gas reserves in order to increase gas supplies to balance the market and sustain exports over a longer period but also, critically, to address the country's energy demand-side challenges. Without the implementation of consistent and integrated energy demand-side management measures, of which price reform is a key one, Egypt could be exposed again to an unpleasant gas supply surplus/deficit cycle. The Egyptian government has already initiated courageous energy price reform measures with some positive results. But it will continue to face challenges with regard to the price subsidy and payment problems of the gas-to-power chain. Fully addressing these issues and liberalizing the country's energy market will, inevitably, take some time, possibly beyond 2030, as this will involve a complex combination of sensitive social, economic and political factors.

The quick answer to the question posed in this paper's title 'Egypt - a return to a balanced gas market?' could be: yes, but not for long. However, this short statement would not do justice to the considerable efforts deployed by all the relevant stakeholders in relaunching Egypt's hydrocarbon segment and bringing on-stream, in a record time, several new gas supply projects. It would also ignore the fact that the answer is only based on current publicly available data and information on both the supply and demand sides.

Egypt holds a central position in East Mediterranean gas developments. It is aiming to become a regional gas export 'hub' to monetize its own natural gas resources and to re-export gas from existing and potential sources of gas supply in neighbouring East Mediterranean countries. In order to achieve this objective, Egypt and its neighbours will have to surmount not only geopolitical and territorial disputes, but also commercial, contractual and inter-governmental agreement challenges in increasingly competitive international gas markets.

Finally, by the end of the next decade and most probably beyond 2030, Egypt's energy portfolio could be transformed with non-hydrocarbon sources of energy capturing an increasing share of the country's electricity generation mix. This could potentially release some additional supplies of natural gas for export but, by then, Egypt will be facing international gas export markets that could be radically different from today's, especially in Europe under a decarbonization agenda. 

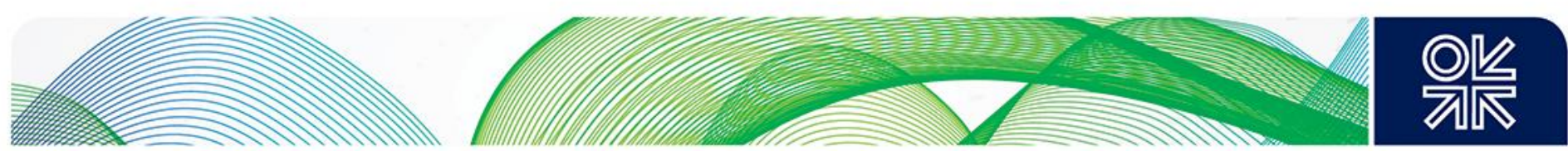

\section{Introduction}

Egypt is the second largest African economy and one of the largest economies in the Middle East and North Africa (MENA) area. It is also one of the biggest energy markets in the Africa and MENA regions with a relatively extensive energy infrastructure, especially for natural gas. In 2015, Egypt became a net natural gas importer after being a key North African exporter of gas supplies for a period of ten years. This unfortunate, but not unexpected, situation was due to a decline in Egypt's natural gas production combined with an unabated rise in domestic gas demand driven mainly by large energy price subsidies. In 2014, the government of Egypt upwardly adjusted all domestic gas prices and is presently engaged in wider reform of domestic energy prices. This is to reduce, and eventually remove by the end of this decade, the huge and unsustainable financial burden of energy price subsidies.

Major changes are taking place on the gas supply side which significantly impact on the country's natural gas balance and the economy in general. Egypt's prospects for gas supply growth were constrained by a set of price and non-price barriers and urgent and drastic action was required to unlock the country's gas supply potential. Given the dominant role of natural gas in Egypt's energy scene, in 2013/2014 the government started implementing a more favourable upstream development policy to reverse the country's declining supply profile. New policy measures helped bring about the discovery of the Zohr field in 2015 and its fast-track development. This field is expected to lead substantial changes in Egypt's natural gas supply dynamics. Several other gas discoveries have been made in recent years in Egypt. Once these newly discovered fields are developed and start producing, they are expected to supply the equivalent of Egypt's current natural gas output.

This contrasts with the gas demand side where, despite serious price and subsidy reforms, Egypt is still facing the same structural difficulties. The financially constrained power sector continues to account for over 60 per cent of total domestic gas use, although efforts are being deployed to diversify the sector's energy source mix. The other large gas users (industries) are now facing commercial challenges under the current higher gas price regime, but several of them still consume a relatively large share of total gas supply. Some industries still rely on gas to generate electricity, or as a reducing agent (e.g. steel industry), or as a feedstock (e.g. fertilisers), while other industries (e.g. cement) have decided to switch to cheaper alternative energy sources (coal).

The regulatory and institutional framework governing the domestic gas market is also being reformed. In August 2017, a new gas market regulatory law was enacted, and it was followed by the promulgation, in February 2018, of executive regulations for the implementation of this law. This is a major step towards the restructuring of Egypt's gas sector and the gradual introduction of a competitive gas market that will further incentivise existing and potential new investors and increase future flows of natural gas supplies.

How these changes and reforms are likely to affect the country's future natural gas balance, including gas export prospects, is a key issue. The objective of the present paper is to review these key changes in Egypt's gas supply and demand sides and to examine their impact on the country's gas balance outlook over the next ten years. The paper will look at the question of how soon Egypt could potentially resume exports of gas supplies and provide some scenarios on the potential levels and time horizons of these exports. The central position that Egypt holds in East Mediterranean gas developments also requires consideration of whether Egypt, with its relatively large gas export infrastructure, could act as an East Mediterranean gas export 'hub'. 

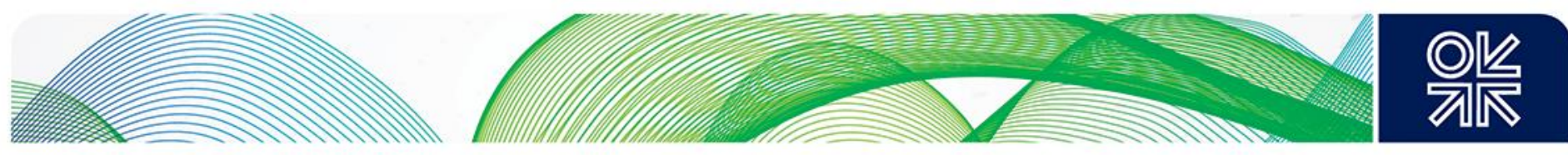

\section{Economic, Regulatory \& Institutional Changes}

\section{Reforming the economy}

The gradual transformation of Egypt's energy sector and, more specifically, its natural gas subsector, is part of the broader economic, regulatory and institutional changes that Egypt is undertaking. This section provides a summary background of the relevant policy decisions and how they pave the way for the revival of Egypt's natural gas industry.

Since the end of the last decade until very recently, Egypt faced a deterioration in its economic situation. Real economic growth dropped significantly. The government public debt continued to increase reaching 103 per cent of gross domestic product (GDP) by the end of $2017^{1}$. There was continued high unemployment; an overvalued currency, and a decline in investments, inter alia. Within the context of this paper, it is important to note that one of the serious constraints faced by the Egyptian economy is the financially unsustainable program of indiscriminate domestic energy price subsidies that prevailed until significant price adjustments were initiated in recent years.

Starting in 2014, the government launched a series of economic reform measures to address these challenges. This included: the VAT law; reduction of energy price subsidies; containing the high growth of the wage bill; floatation of the Egyptian pound; improvement of governance and the investment climate, and the removal of investment barriers to stimulate local and foreign investments. ${ }^{2}$ These measures resulted in the promulgation of several economic reform laws and the floatation of the Egyptian pound in November 2016.

Egypt's economic reform program is endorsed by international institutions, namely the World Bank, the International Monetary Fund (IMF) and the African Development Bank. It is supported by an arrangement under the IMF's Extended Fund Facility (EFF) and is reported to be yielding positive results. In fiscal year 2016/2017, GDP grew by 4.2 per cent compared to 3.5 per cent for the previous year. According to the IMF, in 2017/2018, it is estimated to grow further to 4.8 per cent with a projected average growth rate of six per cent in the medium term. Inflation, which peaked at 35 per cent as a result of the devaluation of the national currency, is expected to decline to about 12 per cent by June 2018. ${ }^{3}$ This favourable assessment by the IMF is subject to maintaining "prudent macroeconomic policies and broadening of growth-enhancing reforms.'

In order to sustain this favourable reform momentum, the IMF highlights a series of policy measures and points out the following: 'This will require the private sector to become the primary engine of growth and the state to provide a stable macroeconomic environment, a friendly business climate and efficient delivery of public goods. Strengthening social protection will also be important to shield the most vulnerable.' ${ }^{4}$ It is worth noting the emphasis on the role of the private sector, which for decades was one of the key beneficiaries of generous energy price subsidies. How would this sector adjust to the reduction, and eventual elimination, of energy price subsidies and how would it affect energyintensive businesses and the national economy in the medium to long-term? At a more disaggregated level these issues, and how they are addressed, will determine the future demand for natural gas, especially gas demand by both the power sector and industries.

In 2014, the government initiated a reform of energy price subsidies with the ambitious objective of phasing out subsidies within five years and their financial impact to reach 0.5 per cent of GDP by

\footnotetext{
${ }^{1}$ IMF Country Report No 18/14, (2018). '2017 Article IV Consultation, Second Review Under the Extended Arrangement Under The Extended Fund Facility, And Request For Modification Of Performance Criteria. Press Release; Staff Report; And Statement By The Executive Director For The Arab Republic Of Egypt'. www.imf.org/ /media/Files/Publications/CR/2018/cr1814.ashx

${ }^{2}$ World Bank (2017). 'Overview of the Egyptian Economy', World Bank website, http://www.worldbank.org/en/country/egypt/overview

${ }^{3}$ See IMF Country Report No 18/14, (2018).

${ }^{4}$ See IMF Country Report No 18/14, (2018).
} 

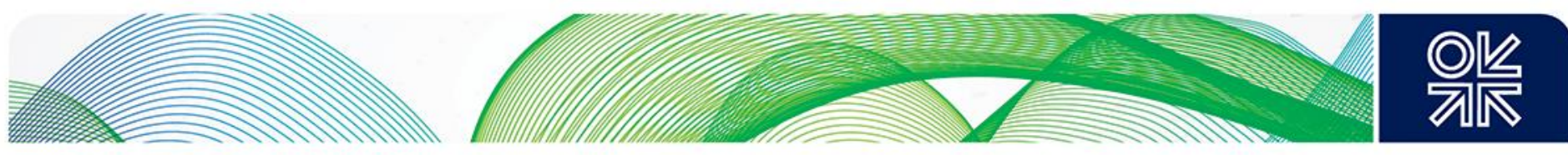

2019. It is indicated that the subsidies that would remain in place would cover only liquid petroleum gases (LPG) and electricity consumed by the poorest households. This target is commendable, but it is unlikely to be reached by $2019 .{ }^{5}$ Financial data released very recently by the government show that energy price subsidies have been reduced significantly for several products and for a range of endusers.

In the fiscal year 2012/2013, energy subsidies accounted for about 22 per cent of total government spending, in 2016/2017 the share was reduced to 14.5 per cent and in 2017/2018 it is estimated it will be further reduced to 11.5 per cent. ${ }^{6}$ For natural gas, the prices of gas supplies to several non-power industrial end-users have been increased considerably (see Table 3). As a result, the overall gas price subsidy burden has been cut significantly. In fact, in some gas consuming sectors, the gas price is reported to be above its delivery cost.

However, it is worth noting, that it is not clear how the reported subsidy figures are calculated, especially for tradable products such as natural gas, oil and oil products, and whether the opportunity cost approach or other approaches have been used. But, there is no doubt that the reform of domestic energy price subsidies will continue to aim at further reducing the country's price subsidy burden.

\section{Energy strategy \& petroleum sector modernisation programme}

In 2014, the government of Egypt launched the formulation of a long-term 'Egypt Vision 2030'. The second pillar of this vision is dedicated to the energy sector and outlines the country's 'Strategic Objectives for Energy to 2030'. It is presented in the table below.

Table 1: Strategic Energy Objectives to 2030

\begin{tabular}{|c|c|}
\hline Objective & Definition \\
\hline Ensuring energy security & $\begin{array}{l}\text { Providing the required energy while } \\
\text { maintaining the aspired growth rates }\end{array}$ \\
\hline $\begin{array}{l}\text { Increasing the contribution of energy sector to the } \\
\text { GDP }\end{array}$ & $\begin{array}{c}\text { Increasing the share of energy sector to the } \\
\text { GDP }\end{array}$ \\
\hline Maximizing utilization of domestic energy resources & $\begin{array}{l}\text { Increasing the energy production of local } \\
\text { resources and maximizing its reliability }\end{array}$ \\
\hline $\begin{array}{l}\text { Enhancing rational and sustainable management of } \\
\text { the sector }\end{array}$ & $\begin{array}{l}\text { Working on the energy mix to reach } \\
\text { international levels }\end{array}$ \\
\hline Reducing the intensity of energy consumption & $\begin{array}{c}\text { Reducing energy consumption rate for all } \\
\text { sectors }\end{array}$ \\
\hline $\begin{array}{l}\text { Limiting the environmental impact of the sector's } \\
\text { emissions }\end{array}$ & $\begin{array}{l}\text { Reducing the levels of sector's emissions } \\
\text { and pollutants }\end{array}$ \\
\hline
\end{tabular}

Source: author's summary sourced from Egypt Vision 2030.7

The strategic energy objectives of Egypt's Vision 2030 underlie several of the government's energy policy decisions looked at in this paper, such as the relaunch of upstream developments and priority for the allocation of natural gas supplies to the domestic market to ensure the country's energy security. As shown above, the diversification of the energy mix is a key objective, especially for the reduction of natural gas consumption in the generation of electricity. Still, it will be challenging to attain this objective within the Vision 2030 time-framework. The reduction of the country's rapid energy consumption growth rate is another key objective, which will need a comprehensive reform of domestic energy prices and a phasing out of subsidies. This is not clearly stated as a key strategic

\footnotetext{
${ }^{5}$ World Bank Report No 110036-EG, (2016). 'Proposed loan in the amount of US\$1,000 million to the Arab Republic of Egypt', 29 November. http://documents.worldbank.org/curated/en/311431482462242135/pdf/1482462241077-000A10458-P161228Egypt-DPF2-PD-Post-Negotiations-29-Nov-12022016.pdf.

${ }^{6}$ MEES (2018). 'Egypt Plans Further Cuts to Energy Subsidies', 20 April. https://www.mees.com/2018/4/20/economics-

finance/egypt-plans-further-cuts-to-energy-subsidies/3f541da0-44b0-11e8-82eb-7bfcbc141485.

7 Government of Egypt (2014). 'Egypt Vision 2030'. http://sdsegypt2030.com.
} 

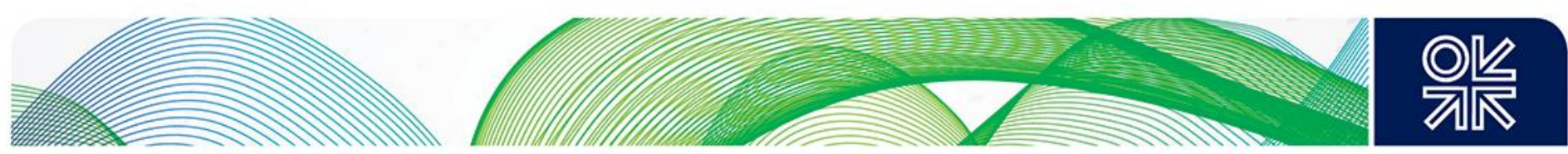

energy objective, but the issue of energy subsidy is addressed in the vision's section on energy (Second Pillar: Energy) and the impact of the heavy financial burden of subsidies is emphasized.

In line with the government's on-going reform measures for the different sectors of the Egyptian economy, the Ministry of Petroleum and Mineral Resources launched recently the 'Oil and Gas Sector Modernization Project.' The stated objective of this programme is to 'Design and implement an integrated transformative program for Egypt's Oil \& Gas sector to enhance its contribution as an engine of economic growth and to reinforce its role as a model for other sectors. ${ }^{8}$ This modernization programme, which is supported by the World Bank and the European Bank for Reconstruction and Development (EBRD), consists of the following six strategic policy measures or priorities:

- Enhancing investment attraction

- Sector structure reform

- Human capital development

- Optimizing downstream performance

- Improving upstream performance

- Promoting Egypt as a regional energy hub

A seventh priority was added more recently focusing on 'decision support and data flow.'9

These strategic priorities, which are presently implemented as separate programmes, are expected to achieve three policy objectives; 'reduction of fiscal deficit, attraction of private sector investments, and provide a role model for the improvement of public sector governance in Egypt.'10

\section{Sector regulation \& institutional changes}

The second key priority of the modernisation programme is the structural reform of the oil and gas industry. Presently, the hydrocarbons sector is regulated by the Ministry of Petroleum and Mineral Resources directly and through its state-owned companies, mainly the Egyptian General Petroleum Corporation (EGPC) and the Egyptian Natural Gas Holding Company (EGAS). The natural gas subsector, which is the dominant hydrocarbon segment in Egypt's oil and gas scene, is currently undergoing a fundamental transformation.

Until very recently, Law No. 217 of 1980 and its executive regulations covered natural gas activities in Egypt. Under this gas law, EGAS was assigned the responsibility of all operations relating to the transportation (through the national gas grid operated by its subsidiary company GASCO) and domestic supply of natural gas to power plants, industry and residential users. Private companies registered under Egyptian law were also allowed to construct and operate domestic gas pipelines but, according to the 1980 gas law, these activities are subject to approval and monitoring by EGAS.

In August 2017, a new law on the regulation of midstream and downstream gas market activities was promulgated and its executive regulations were issued in February 2018. The new gas market law regulates all gas market activities in Egypt, except the petroleum sharing agreements with supplies covered under long-term gas sales contracts. According to the new 2017 gas law, entities operating in the above-mentioned gas market segments should apply for licenses to be issued by the new gas market regulatory authority. The length of transition periods stipulated by this new gas law for compliance varies between five and eight years depending on the nature of the relevant businesses' activities.

\footnotetext{
${ }^{8}$ Ministry of Petroleum \& Mineral Resources (2017). ‘Egypt Oil \& Gas Modernization Project', June. ${ }^{9}$ Ministry of Petroleum \& Mineral Resources (2017). 'Egypt Oil \& Gas Modernization Project', June. ${ }^{10}$ World Bank (2017). 'Egypt: Supporting the Petroleum Sector Modernization Program', 18 April. http://documents. worldbank.org/curated/en/684491507150472272/pdf/120258-WP-P162782-PUBLICActivityCompletionSummaryincludingfinalizeddeliverablesP.pdf
} 

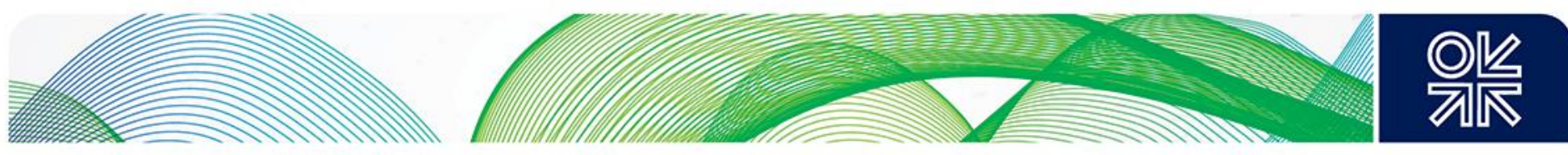

In 2017, it was announced that the market would be fully liberalised by $2022 .{ }^{11}$ Reaching such a level of gas market maturity and liberalisation has taken decades in the case of the US and West European gas markets. In Egypt, the process is likely to take longer than the initial target of five years. But Egypt could look at the experiences of countries that have liberalised their gas markets and the challenges that they faced. Although market liberalisation experiences vary from one country to another, one of the key lessons, for example, from the successful liberalization of North Western European gas markets has been to allow for an appropriate timeframe for the unbundling of gas activities. ${ }^{12}$

It should be stressed that the enactment of this new gas law is an important positive first step forward in the restructuring of Egypt's natural gas sector. The law includes a critical set of reform measures that other gas producing countries in the Middle and North Africa region are reluctant to undertake or slow to implement, with their focus limited to the adjustments of petroleum product prices only. ${ }^{13}$ The August 2017 law establishes a new authority for the regulation of gas market activities, the Gas Market Regulatory Authority, and the head of this regulatory body has already been appointed. The regulatory authority will monitor and regulate all gas market activities in Egypt, except the abovementioned petroleum sharing agreements. The chairman of the board of this regulatory authority is the Minister of Petroleum and Mineral Resources and key regulatory decisions will require the minister's approval, and that of the Cabinet, before these decisions can be issued and implemented.

A key feature of this new law is that it allows private sector entities to procure and market their own gas supplies directly without going through EGAS, which until now has played the role of national aggregator of gas supplies to the domestic market. It should be noted that a few private companies applied and obtained the right to import their own gas supplies before the issuing of the new 2017 gas market regulations law.

The liberalisation of the procurement process is a major step towards increasing gas supply availability to the domestic market and to removing/reducing the financial burden on state-owned entities, such as EGAS, of procuring, transporting (through GASCO) and managing gas supplies to domestic gas users. But, it raises a number of key issues that need to be addressed.

Under the new gas law, EGAS will no longer play the role of national gas supplier. Who would then be eligible to procure and/or sell its own gas supplies directly? How will gas supplies be allocated? How will customers be allocated between EGAS and private suppliers? Domestic gas prices are currently set by prime ministerial decree. How will prices be set under the restructured new regime? What will be the Take or Pay conditions? What tax regime will apply to direct gas supply sales to encourage competition and new market participants? How will the unbundling - a concept embraced by the new gas market law - of different gas activities be implemented? What are the detailed terms and conditions of access to the country's natural gas transmission network (GASCO's role vis-à-vis the incumbent and the new market players)?

The above questions are just some of the key issues raised with respect to the implementation of the new gas law. It is expected that the new executive regulations and rules and directives to be issued by the new gas market regulatory authority will address these issues.

\footnotetext{
${ }^{11}$ Al-Shorouk, 15 November 2017. 'Full liberalization of Egypt's natural gas market by 2022'.

${ }^{12}$ Heather, P, (2015). 'The Evolution of European traded gas hubs', Oxford Institute for Energy Studies, OIES NG104.

13 'MENA Energy Pricing Reforms', OIES, Oxford Energy Forum, Issue 108, March 2017.
} 

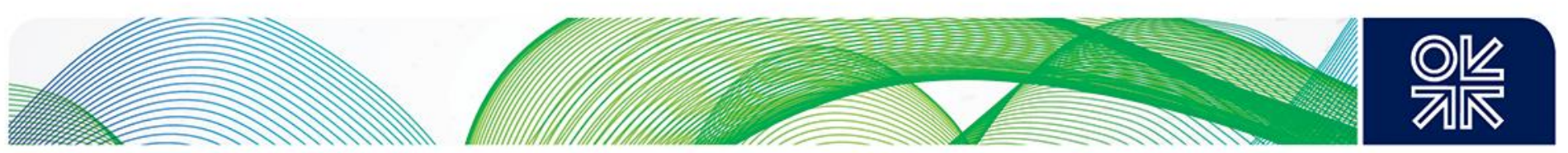

\section{Natural Gas Supply - Major Developments}

\section{Key drivers of upstream development relaunch}

The previous section provides an overview of the major economic, regulatory, and institutional developments that form the underlying framework for the transformation of Egypt's energy sector in general and its natural gas market in particular. This section focuses on the key drivers that have enabled the relaunch of Egypt's upstream hydrocarbon segment, especially its natural gas supply part.

Following the 2011 Revolution, the Egyptian government finally realised that the country's natural gas balance would continue to be adversely affected by the decline in indigenous gas production, and a rapidly growing domestic gas demand, unless drastic actions were taken. As a result of this, the government made increasing the availability of gas supplies for the domestic market its top priority. It allowed the import of LNG supplies, as an immediate and temporary measure; reduced and later stopped gas exports and started addressing the key factors that had led to the decline in domestic production. The government concentrated its efforts on the relaunch of upstream gas development with priority, as mentioned above, given to supplying the domestic market. This marked a significant shift in Egypt's natural gas supply policy compared to previous government policy which had allocated one-third of the reserves for the domestic market, another third for exports, whilst the remaining third was to be reserved for future generations. ${ }^{14}$

\section{Gas pricing mechanism}

Adjustments of the model production sharing agreement took place ahead of a new licensing round issued in 2012. This round failed to draw a lot of interest and had to be extended to early 2013. Therefore, there was a need for further discussions with all stakeholders to determine what other adjustments were required. Among the key adjustments, which were carried out in stages, was the critical revisiting of the gas pricing mechanism. Previously, the pricing of the share of gas supplies purchased from the international oil companies (IOCs) was linked to the oil price (initially to the price of Gulf of Suez blend and then to the Brent price) with floor and ceiling limits applied to all agreements regardless of the gas supply cost incurred. Responding to the concerns and reluctance of the IOCs to invest in high-risk high cost upstream projects, the government allowed the pricing structure to be agreed between the IOCs and EGAS to take into account the development cost and the upstream project return for new discoveries and developments. As a result, the new pricing mechanism enables the gas supply prices to reach levels of up to about $\$ 6 / \mathrm{MMBtu}$ (see table below) depending on the Brent price linkages. Again, this was conducted in stages reflecting the length of the negotiation process and the challenging institutional procedures that such amendments required within the Egyptian legal and institutional framework.

\section{Payment of government arrears}

Another key driver that aided the relaunch of upstream development in Egypt is the gradual payment of government arrears to international oil companies. The arrears represent the debts accumulated by the state-owned companies EGPC and EGAS for hydrocarbon supply payments owed to the IOCs. These arrears peaked at a level of $\$ 6.3$ billion by the end of 2013 and, as of October 2017, were reduced to $\$ 2.3$ billion. Presently (Q2 2018), the total is reported to be $\$ 2$ billion. But depending on payment conditions, price movements, and production growth, this total could be increasing. The government aims to clear these arrears completely by 2019 and not accumulate any new debt. This objective may prove difficult to achieve given the fact that domestic energy prices remain subsidized for a large share of the volumes of hydrocarbon consumed, despite the price increases that have

\footnotetext{
${ }^{14}$ Aissaoui, A, (2013). 'Between a Rock and a Hard Place: Egypt's New Natural Gas Supply Policy', APICORP's Economic Commentary, Vol. 8 No. 3, March, 13-17. http://www.apicorp-arabia.com/Research/Commentaries/2013/e-

Book\%20Economic\%20Commentary\%20Vol\%208\%202013.pdf.
} 

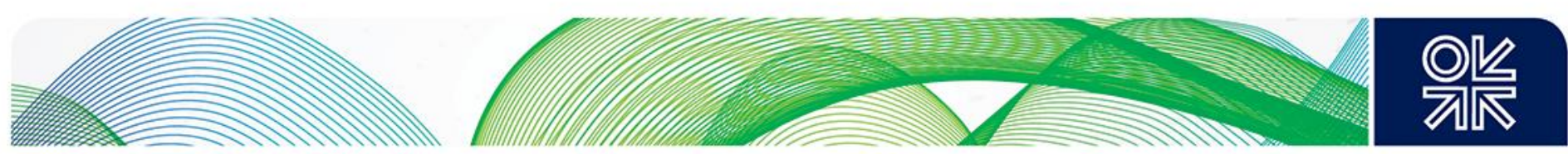

taken place since 2014, and because of the expected significant increase in natural gas production by $2019 / 2020$.

Table 2: Gas Supply Prices

\begin{tabular}{|l|c|c|}
\hline \multicolumn{1}{|c|}{ Company } & Area & Price (\$/MMBtu) \\
\hline Edison & Mediterranean & $5.88\left(^{*}\right)$ \\
\hline $\begin{array}{l}\text { Shell WDDM } \\
\text { (Future Phases, incl. Phase 9B) }\end{array}$ & Mediterranean & $5.88\left(^{*}\right)$ \\
\hline Eni (new discoveries) & Mediterranean & 4.00 to $5.88\left(^{*}\right)$ \\
\hline Shell/Apache (shale gas) & Western Desert & $5.45\left(^{*}\right)$ \\
\hline \multicolumn{2}{|c|}{ New Minimum Price for Gas Discoveries } & $3.95\left(^{* *}\right)$ \\
\hline
\end{tabular}

$\left({ }^{*}\right)$ : The price listed is likely to indicate a price range or the maximum price level that could be reached under the agreed gas pricing mechanism.

$\left.{ }^{* *}\right)$ : Increased from previous price of $\$ 2.65 / \mathrm{MMBtu}$

Source: MEES (2018). ${ }^{15}$

\section{Institutional bureaucracy}

One major constraint that is not always clearly reported or fully appreciated, which considerably affects the time it takes to implement a project, is the presence of several layers of institutional bureaucracy that both state-owned and international oil and gas companies have to go through for the different project approval and implementation stages. This constraining bureaucratic system delays projects significantly and discourages new or expanded project investments. Consequently, the government has had to intervene, sometimes at a very high level, to address this issue and move projects forward. This strong government support to tackle this barrier is acknowledged by international oil companies operating in Egypt. It is considered as one of the key drivers that have helped move forward upstream projects.

\section{Key gas discoveries and new developments}

During the last five years, the Egyptian government is reported to have signed a total of over 80 exploration and production agreements with international oil companies. The above-mentioned key drivers were critical to the relaunch of upstream hydrocarbon development in Egypt and have facilitated the fast-track start of natural gas production from the Zohr, West Nile Delta (WND) and Atoll fields providing a much-needed boost to Egypt's indigenous gas production.

Zohr

At the end of August 2015, Italy's Eni announced that it had made a world class supergiant gas discovery at its Zohr Prospect, in the deep waters of Egypt. The discovery well Zohr 1X NFW is located in the economic waters of Egypt's Offshore Mediterranean, in 4,757 feet of water depth $(1,450$ metres), in the Shorouk Block. The agreement was signed in January 2014 between the Egyptian Ministry of Petroleum and Mineral Resources and the Egyptian Natural Gas Holding Company (EGAS), following a competitive international bid round. ${ }^{16}$

The same Eni announcement indicated that based on 'the well and geophysical data available, the field could hold a potential of 30 trillion cubic feet of lean gas in place'. The stakes of the Shorouk block are held by Eni ( 60 per cent), Russia's Rosneft (30 per cent) and BP (10 per cent). In March 2018, Eni announced the reduction of its stake to 50 per cent by agreeing to sell 10 per cent of its Shorouk concession to the UAE's Mubadala Petroleum, subject to approval by the Egyptian

\footnotetext{
${ }^{15}$ MEES (2018), 'Egypt Gas Turns The Corner, But Can It Maintain Investment?', 16 February.

${ }^{16}$ Eni (2015). 'Eni discovers a supergiant gas field in the Egyptian offshore, the largest ever found in the Mediterranean Sea',

Eni press release, 30 August.

https://www.eni.com/docs/en_IT/enicom/media/press-release/2015/08/PR_EniEgypt_eng.pdf.
} 

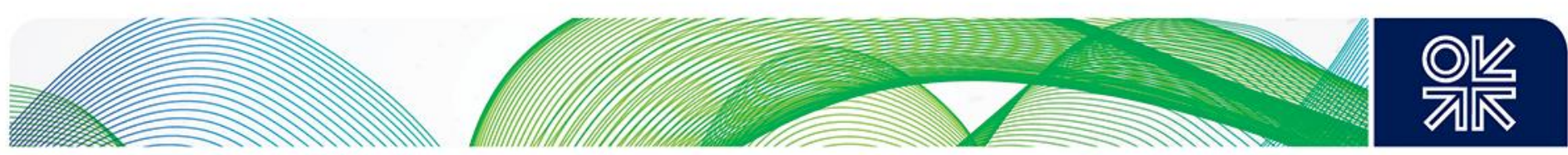

authorities. ${ }^{17}$ The Shorouk block with the Zohr field is operated by Belayim Petroleum Company or Petrobel (a joint venture of Eni's Egypt subsidiary IEOC and EGPC) on behalf of Petro Shorouk (jointly-owned by Eni and its partners and Egypt's EGAS). ${ }^{18}$

Less than three years after announcing this major gas discovery, Eni issued a press release on 20 December 2017 indicating that it had produced its first gas from the Zohr field. ${ }^{19}$ This record time between discovery and the start of gas production is the result of a combination of factors involving Eni's successful exploration, appraisal, development, and contracting strategies, and also due to strong support from the Egyptian government. The discovery of the offshore Zohr field is by far the largest gas discovery made in Egypt and in the whole Mediterranean region. Maximum production from the Zohr field is planned to reach 2.7 billion cubic feet a day (Bcf/d). It is expected to have a significant impact on Egypt's gas balance and has encouraged further exploration and a renewed interest in the areas near the Shorouk block. But, other discoveries and developments have also taken place or are currently taking place in Egypt's offshore area.

\section{West Nile Delta}

The West Nile Delta (WND) development project presently consists of three phases or projects covering five offshore gas and condensate fields in the North Alexandria and West Mediterranean Deepwater blocks. Phase 1 covers the development of the Taurus and Libra fields, whilst Phase 2 includes the Fayum and Giza fields that will be developed through the existing Rosetta plant after the necessary modifications have been carried out. Phase 3 will consist of the development of the Raven field requiring the construction of new onshore facilities. The WND stakeholders are BP (82.75 per cent) and DEA (17.25 per cent) and the project is operated by BP. According to BP, the WND project will develop 5 trillion cubic feet (Tcf) of gas resources with a maximum production level of about 1.5 Bcf/d. ${ }^{20}$ The Taurus and Libra fields started producing gas in May 2017 and the Giza, Fayoum and Raven fields are expected to come on-stream by the end of 2018 or beginning of 2019.

The WND development programme will yield the second highest level of natural gas supply in Egypt after the Zohr project. Other discoveries have been made in the WND area, but present development is limited to the five fields. BP believes that there is the potential to expand WND gas production and other discovered resources and to continue its exploration programme and follow-on, in order to maintain its production levels in Egypt to 2030 and beyond. ${ }^{21}$

\section{Greater Nooros}

Among the relatively recent upstream developments are the fields being developed in the Greater Nooros Area which includes the Nooros and Baltim South West fields. The area is being developed by Nidoco, a joint venture company formed of Eni's Egypt subsidiary IEOC, BP and EGPC. Petrobel is operating the area on behalf of Nidoco. Production from Nooros, a Nile Delta offshore field, started in 2016 and is currently producing over 1 billion cubic feet a day. Baltim South West is also an

\footnotetext{
${ }^{17}$ Eni (2018). 'Eni sells to Mubadala Petroleum a 10\% stake in the Shorouk concession, offshore Egypt', Eni press release, 11 March. https://www.eni.com/en_IT/media/2018/03/eni-sells-to-mubadala-petroleum-a-10-stake-in-the-shorouk-concessionoffshore-egypt.

${ }^{18}$ Eni (2017). 'Eni begins producing from Zohr, the largest ever discovery of gas in the Mediterranean Sea', Eni Press Release, 20 December. https://www.eni.com/en_IT/media/2017/12/eni-begins-producing-from-zohr-the-largest-ever-discovery-of-gas-inthe-mediterranean-sea.

19 Eni (2017). 'Eni begins producing from Zohr, the largest ever discovery of gas in the Mediterranean Sea', Eni Press Release, 20 December. https://www.eni.com/en_IT/media/2017/12/eni-begins-producing-from-zohr-the-largest-ever-discovery-of-gas-inthe-mediterranean-sea.

${ }^{20}$ BP (2017). 'BP announces start of production from West Nile Delta development achieving first gas eight months ahead of schedule and production 20 per cent above plan', BP press release, 10 May.

https://www.bp.com/en/global/corporate/media/press-releases/bp-announces-start-of-production-from-west-nile-deltadevelopment.html.

${ }^{21}$ BP (2015). 'BP finalises deal to develop Egypt's West Nile Delta gas fields', BP press release, 6 March

https://www.bp.com/en/global/corporate/media/press-releases/bp-finalises-deal-develop-egypt-nile-delta.html.
} 

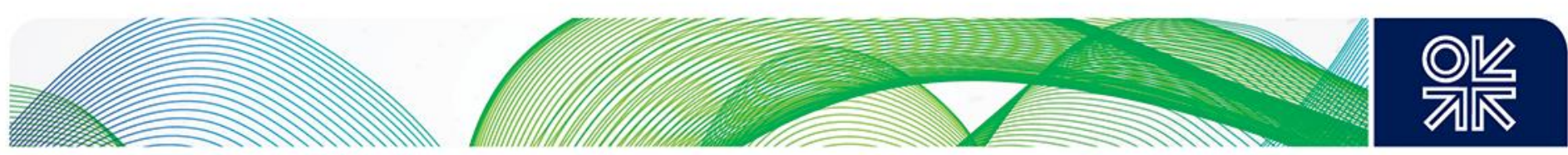

offshore field located near Nooros in the Nile Delta. It was discovered after Nooros and gas production is expected to start at the end of this decade.

Atoll

Another promising upstream gas development is that of the Atoll offshore field discovered in March 2015 and located in the North Damietta area. The Atoll development is led by BP and operated by the Pharaonic Petroleum Company (PhPC). PhPC is a joint venture between BP, Eni and EGAS. Atoll's Phase 1 is an early production scheme. It started producing 350 million cubic feet a day (Mcf/d) in February 2018, less than three years after discovery and seven months ahead of schedule. ${ }^{22}$ According to BP, the decision to invest in the development of a second phase of the Atoll project is yet to be taken and would depend on the performance of the project's first phase. ${ }^{23}$

\section{WDDM - Burullus Phase 9B}

Among the key expansion projects presently under consideration is the Burullus Phase 9B project in the West Delta Deep Marine (WDDM) concession, which has now reached financial investment decision (FID) and is going ahead. ${ }^{24}$ The two WDDM stakeholders are Shell (50 per cent), which absorbed BG's share, and Petronas (50 per cent). The Burullus field is operated by the Rashid Petroleum Company/Burullus Gas Company (Rashpetco), a joint venture company between EGPC (50 per cent), Shell (25 per cent) and Petronas (25 per cent). Work on the development of the Burullus Phase 9B project was stopped in 2016 due to disagreements between Shell/Petronas and the government on the price of gas to be delivered to the domestic gas market as well as on Shell's gas share. It is reported that a settlement addressing these issues was reached and project activities will be resumed shortly with first gas production from this project's Phase 9B scheduled for the end of 2018. ${ }^{25,26,27}$ The maximum gas production for this phase of the Burullus project is expected to reach about 350 to 400 million cubic feet a day (Mcf/d) by the end of this decade.

\section{Other planned developments}

Other new developments are planned by the government for the next five years as part of the Ministry of Petroleum and Mineral Resources' plans to implement 11 gas projects worth $\$ 17.5$ bn by $2023 .{ }^{28}$ These include the following projects/fields: West El Burullus; South Seth and North Tort; Salamat; Rahmat; Satis; Tennin; Merit; Aten; Tersa and Salmon. According to the ministry, all these projects would provide an additional total supply of gas of about 1.3 billion cubic feet a day by the early 2020s. However, there is no information on how these projects would be implemented, the companies that would be involved, etc.

\section{Gas supply profile scenarios}

Egypt's projected gas supply outlook over the next ten years will depend mainly on the successful implementation of all the above-mentioned natural gas supply projects. This implementation needs to leverage not only the key drivers that enabled the country to relaunch the development of its upstream hydrocarbon activities in an impressive way, but also to adapt to changes in local, regional

\footnotetext{
22 Initial production of $200 \mathrm{MMcf} / \mathrm{d}$ was tested in December 2017.

${ }^{23} \mathrm{BP}$ (2016). 'BP sanctions 'fast-track' development of Atoll discovery in Egypt', BP press release, 20 June.

https://www.bp.com/en/global/corporate/media/press-releases/bp-sanctions-fast-track-development-of-atoll-discovery-inegypt.html.

${ }^{24}$ Interfax (2018). 'Shell takes FID on Phase 9B of West Delta Deep Marine', 18 April.

http://interfaxenergy.com/gasdaily/article/30497/shell-takes-fid-on-phase-9b-of-west-delta-deep-marine.

${ }^{25}$ Egypt Oil \& Gas (2017). 'Shell, Petronas Develop Burullus 9B Phase', 20 February. http://egyptoil-gas.com/news/shellpetronas-develop-burullus-9b-phase/.

${ }^{26}$ Egypt Oil \& Gas (2017). 'Shell Renegotiating Burullus Contract', Egypt Oil \& Gas, 19 December. http://egyptoilgas.com/news/shell-renegotiating-burullus-contract/.

${ }^{27}$ Egypt Oil \& Gas (2018). 'Petroleum Sector to Start Natural Gas Production from West Delta 9B Phase', 19 March. http://egyptoil-gas.com/news/petroleum-sector-to-start-natural-gas-production-from-west-delta-9b-phase/

${ }^{28}$ Daily News Egypt (2017). 'Petroleum Ministry plans to implement 11 gas projects worth $\$ 17.5 \mathrm{bn}$ until 2023', 28 November. https://dailynewsegypt.com/2017/11/27/petroleum-ministry-plans-implement-11-gas-projects-worth-17-5bn-2023/.
} 

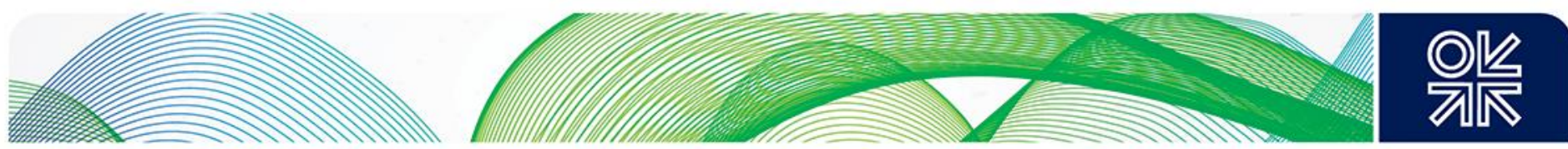

and global market conditions. There is no disaggregated data in the public domain on the potential medium to long-term natural gas supply profiles of Egypt's existing and future gas producing fields. Although, it is not the objective of this paper to produce projections of natural gas supply, two high level gas supply scenarios are presented to provide an indication of the potential evolution of natural gas supply in Egypt over the next ten years. These scenarios are based on the aggregated data that has been reported by the government, trade press, and other public sources. ${ }^{29}$

The two supply profile scenarios cover a period of ten years from 2018 to 2027 . The first supply scenario (A) includes existing legacy producing fields, taking into consideration the decline rate of mature fields, plus new production from the following gas supply projects:

- Zohr

- West Nile Delta (WND)

- Greater Nooros Area

- Atoll Phase 1

- WDDM - Burullus Phase 9B

In addition to the above-listed existing and new gas supply projects, the second supply scenario (B) incorporates other potential new discoveries and developments announced by the government and assumed to come on-stream at the beginning of next decade and could add an average of between 1.0 and $1.5 \mathrm{Bcf} / \mathrm{d}$ of incremental gas supply. As mentioned above, the Ministry of Petroleum and Mineral Resources is reported to have identified 11 new gas supply projects that would add a total of about $1.3 \mathrm{Bcf} / \mathrm{d}$ by 2023 , but there is no information on their planned implementation. ${ }^{30}$ Thus, this second optimistic, or rather speculative supply scenario, takes into consideration these announced, but yet to be confirmed, additional natural gas supplies. The two proposed supply profile scenarios are presented in the following figures.

\section{Figure 1: Egypt Gas Supply Profile - Scenario A (Bcf/d, averages)}

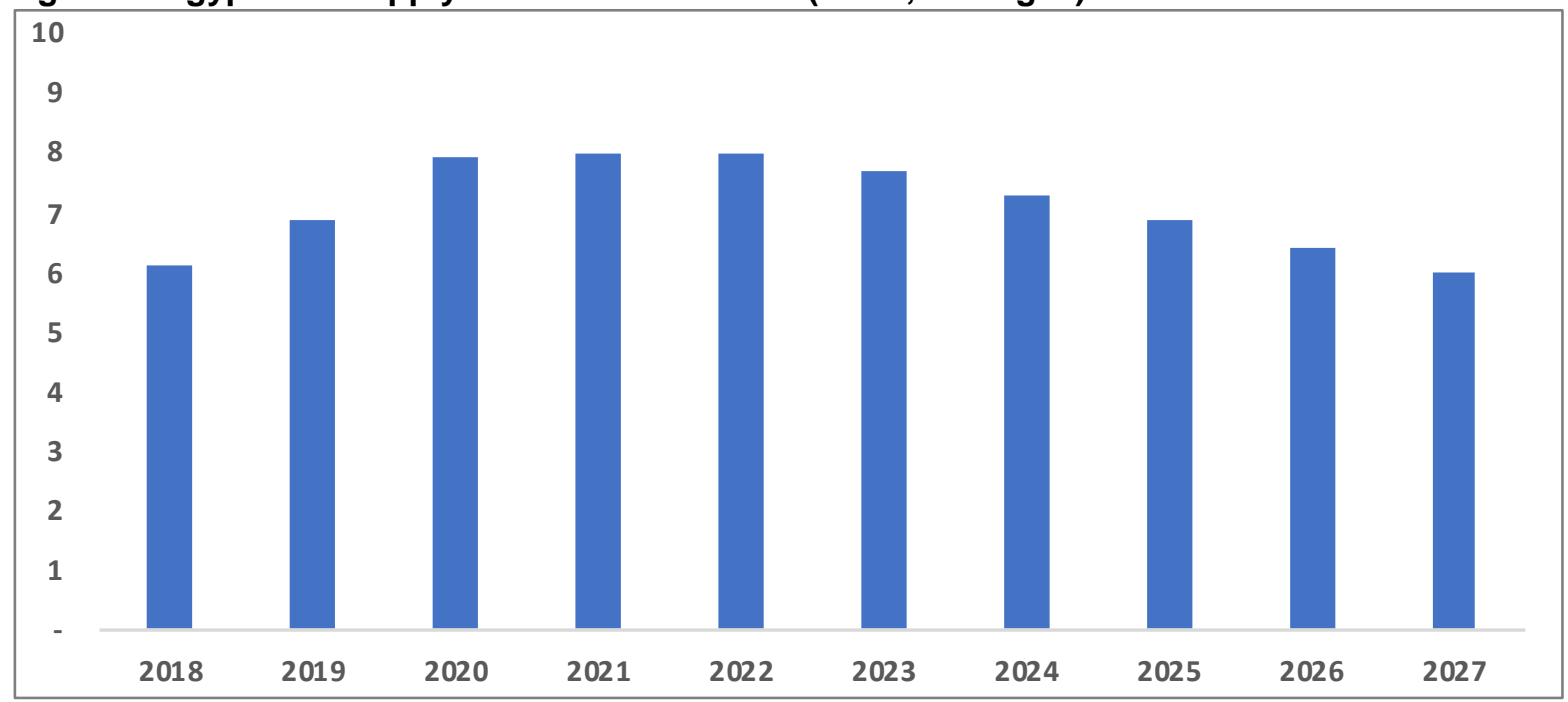

Source: author's estimation

\footnotetext{
${ }^{29}$ It is assumed that the reported natural gas supply data are net or marketed gas production levels

${ }^{30}$ See footnote 28.
} 

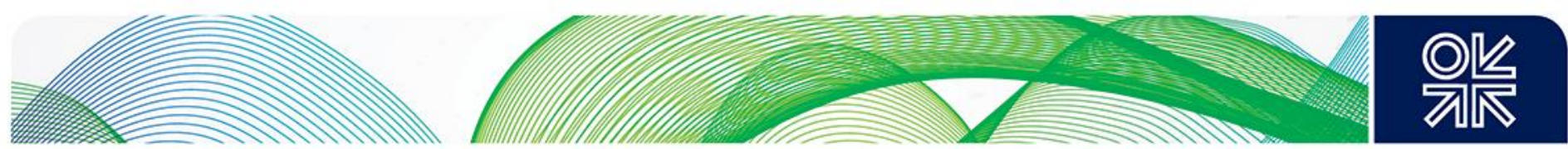

Figure 2: Egypt Gas Supply Profile - Scenario B (Bcf/d, averages)

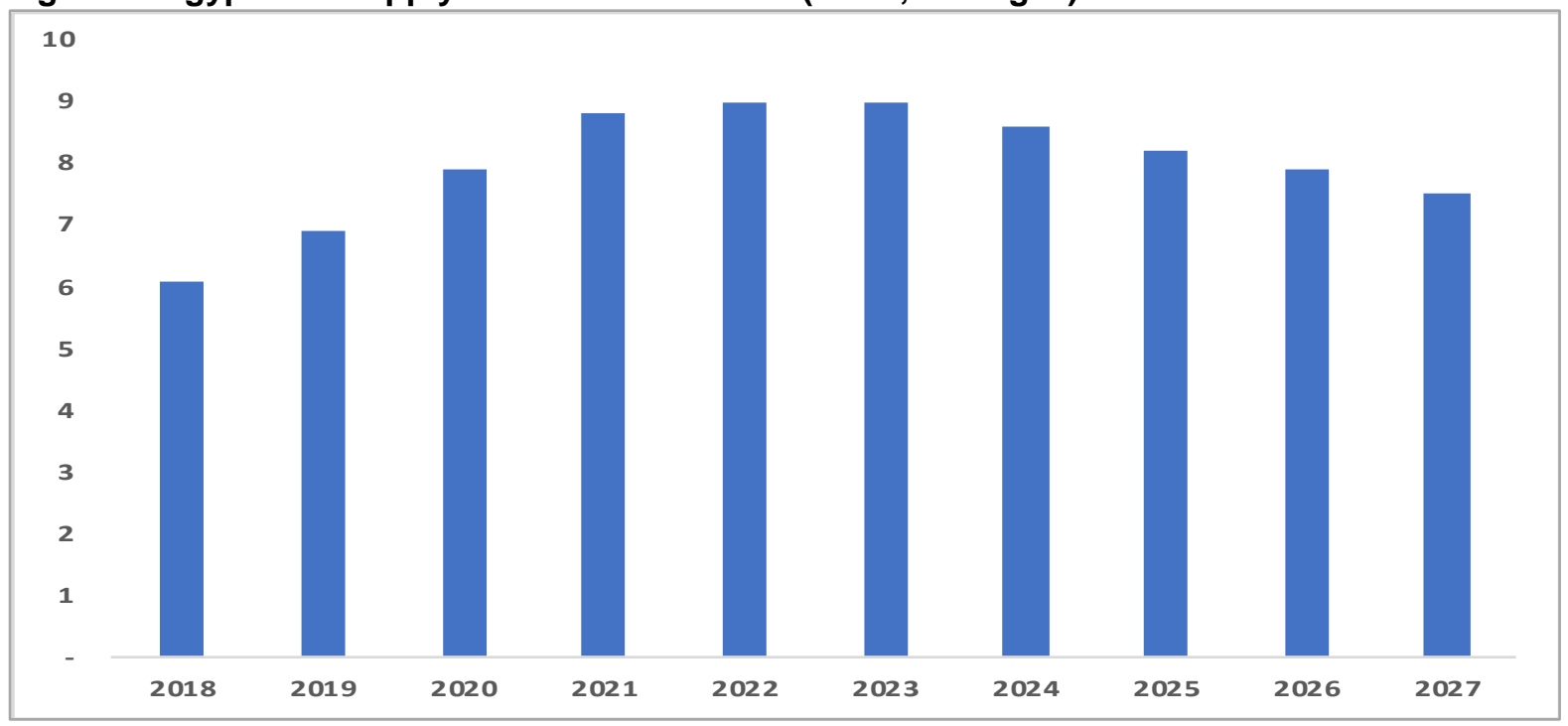

Source: author's estimation

It is clear that these two scenarios do not cover all possible supply outcomes. Over time, the production performance of fields will depend on a number of factors - related and unrelated to a field's reservoir performance - that are not always easy to identify at the preliminary stage of development planning. New discoveries may not be developed as initially announced for commercial, technical and sometimes non-commercial reasons, fields could follow different depletion patterns, and so on. Furthermore, it is not unusual that in some cases, publicly reported projected production figures may not reflect the final approved development plans and more realistically achievable and sustainable production profiles. 

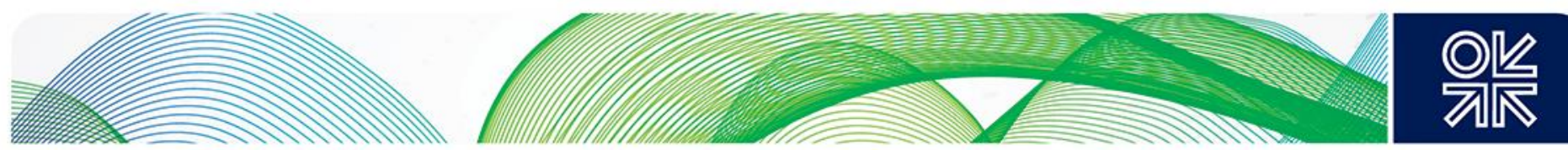

\section{Domestic Gas Demand}

\section{Energy demand overview}

The rapid growth of domestic demand for natural gas was one of the most difficult challenges faced by the Egyptian government in the management and restructuring of Egypt's energy sector and its long-term sustainable development. Despite the much-reduced gas demand growth over the last ten years, due to a shortage of gas and an economic recession, Egypt's domestic gas market continues to consume a relatively large volume of gas, especially to generate electricity. This section outlines the key elements of this domestic gas demand by category of users and proposes a demand outlook over the next ten years. Before focusing on natural gas demand dynamics, this section starts with an overview of the country's total energy demand and the government's plans for a potential diversification of the energy mix.

Egypt's consumption of primary energy supply grew at a compound annual growth rate (CAGR) of about three per cent between 2005 and 2015 (latest available data). It reached 80 million tonnes of oil equivalent (toe) in 2015. Fossil fuels continue to account for more than 95 per cent of this primary energy consumption. As shown in the figure below, oil and natural gas are, by far, the main primary sources of energy supplied and consumed in Egypt. Renewable energy (solar and wind) presently covers much less than half a per cent of total primary energy use. Solid biofuels account for just over two percent of Egypt's total primary energy supply.

Figure 3: Egypt's Primary Energy Supply (2015)

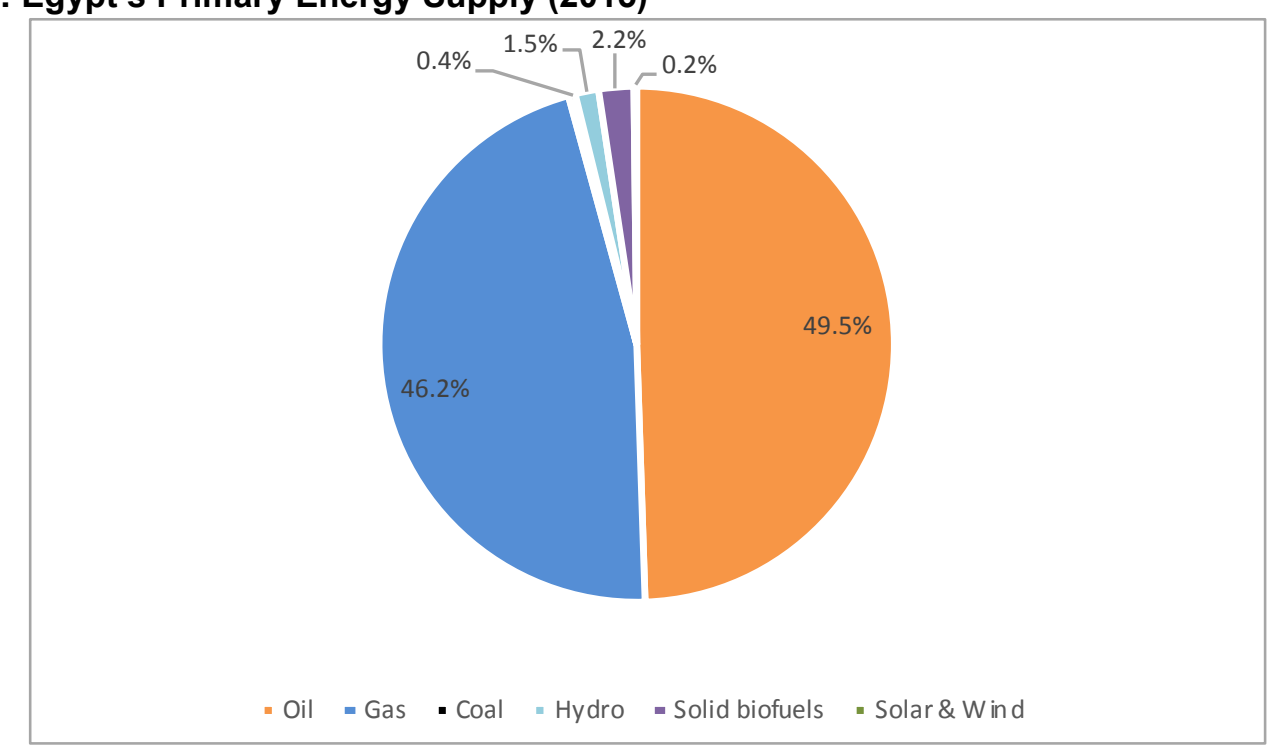

Source: IEA (2017).

Over the last decade, there have been several policy measures announced by the government to develop sources of renewable energy (solar and wind). The objective was to reach 20 per cent of electricity supply to be produced from renewable sources, initially by 2020. This target date was later moved to 2022. In December 2017, the Ministry of Electricity and Renewable Energy announced that 'Egypt will produce 42 per cent of its electricity from renewable resources by 2025.'31 If this latest target is confirmed, it would be an even more ambitious one to attain given the current very low level of electricity supply generated from solar and wind energy sources.

\footnotetext{
${ }^{31}$ Bloomberg (2017). 'Egypt to Generate 42\% of Electricity from Renewables by 2025', 18 December. https://www.bloomberg.com/news/articles/2017-12-18/egypt-to-generate-42-of-electricity-from-renewables-by-2025.
} 

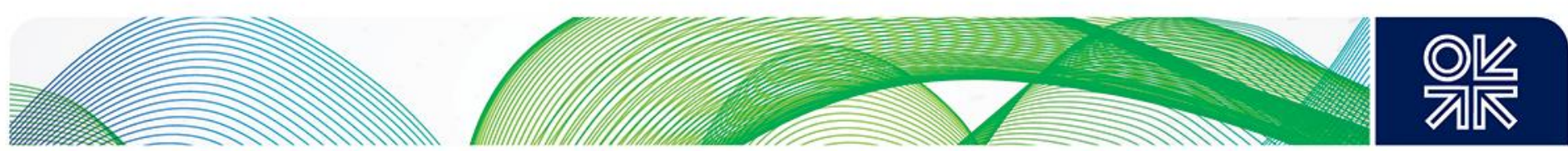

Nevertheless, a lot of effort is presently deployed to focus on the development of sources of renewable energy and this effort is strongly supported by large international financing organisations. The World Bank's International Finance Corporation (IFC) is planning to invest about $\$ 700$ million in renewable energy projects in Egypt and is already financing 13 solar projects. The European Bank for Reconstruction and Development (EBRD) approved a budget of $\$ 500$ million for the development of private renewable energy projects and is presently lending a total of about $\$ 400$ million to finance 16 solar projects. ${ }^{32,33}$ These solar energy projects will provide a total of 1,400 MW of solar energy capacity. In February 2018, it was announced that Egypt had awarded electricity generation licences for the development of four wind farms with a combined capacity of 1,420 MW. ${ }^{34}$ These are encouraging developments that act as catalysts for additional renewable projects. In the long-term all these renewable energy projects will hopefully help reduce Egypt's heavy dependence on gas-fired electricity generation.

Other new sources of electricity supply are being looked at again. More than ten years ago, the Egyptian government started planning for the development of nuclear power plant capacity, but little progress had been made. Finally, at the end of 2017, Egypt signed a $\$ 30$ billion agreement with Russia to develop a 4,800 MW nuclear power plant at the El Dabaa site (west of Alexandria). The plant's units are planned to be commissioned in 2026 and 2028. However, the implementation of such a large and complex project within the announced time framework could be extremely challenging.

In order to further diversify the country's mix of electricity generation sources, the Egyptian government is also considering the development of coal-fired power plant capacity. The Egyptian Electricity Holding Company (EEHC) is negotiating with Al Nowais, a company from the United Arab Emirates, for a 2,650 MW coal-fired project to be sited at Ouyoun Moussa in the Suez area. ${ }^{35}$ In March 2018, it was also announced that EEHC was evaluating bids submitted by three international groups for the development of a 6,600 MW coal-fired power plant at Hamrawein on the Red Sea coast. ${ }^{36}$

When the Aswan High Dam in Upper Egypt was completed in the early 1970s, hydro-power became the country's main source of electricity supply. But hydro-electric production currently covers only a small share of Egypt's electricity output (seven per cent of electricity generated in 2015/2016), far below the output share of oil and gas-fired thermal power plants. Uncertainties related to the future availability of water resources from the Nile River, ${ }^{37}$ and the country's increasing demand for water supplies driven by a rapid rise in population, are likely to further constrain the potential supply of electricity from Egypt's hydro power plants. Presently, thermal power plants using oil and natural gas are the main sources of generating fuels and natural gas accounts for more than 70 per cent of all the electricity generated in Egypt.

\section{Natural gas demand}

\section{Domestic gas pricing \& challenges}

One of the common dilemmas that producers of energy resources face in developing economies (and at one point in centrally planned economies) is how to allocate the rent that would be generated from the production and sale of these resources and how it would affect the different sectors of the national

\footnotetext{
32 European Bank for Reconstruction \& Development (2017). 'EBRD approves US\$ 500 million for private renewable projects in Egypt', 8 June. http://www.ebrd.com/news/2017/ebrd-approves-us-500-million-for-private-renewable-projects-in-egypt.html. ${ }^{33}$ Bloomberg (2017) 'Egypt Draws \$1.8 Billion Investments for 1.4 Gigawatts of Solar', 18 October.

https://www.bloomberg.com/news/articles/2017-10-18/egypt-draws-1-8-billion-investments-for-1-4-gigawatts-of-solar.

${ }^{34}$ Renewables Now (2018). 'Egypt licenses 1,420 MW of wind power generation', 16 February.

https://renewablesnow.com/news/egypt-licenses-1420-mw-of-wind-power-generation-601998/.

${ }^{35}$ Enterprise Press (2017). 'Electricity Ministry allocates land for AI Nowais' USD 4 bn coal plant', 10 December.

https://enterprise.press/stories/2017/12/10/electricity-ministry-allocates-land-for-al-nowais-usd-4-bn-coal-plant/.

${ }^{36}$ Daily News Egypt (2018). 'EEHC to complete evaluating financial bids for Hamrawein power plant in March', 8 March.

https://cdn1.dailynewsegypt.com/2018/03/08/eehc-complete-evaluating-financial-bids-hamrawein-power-plant-march/.

${ }^{37}$ The Nile river is Egypt's main source of water supply.
} 

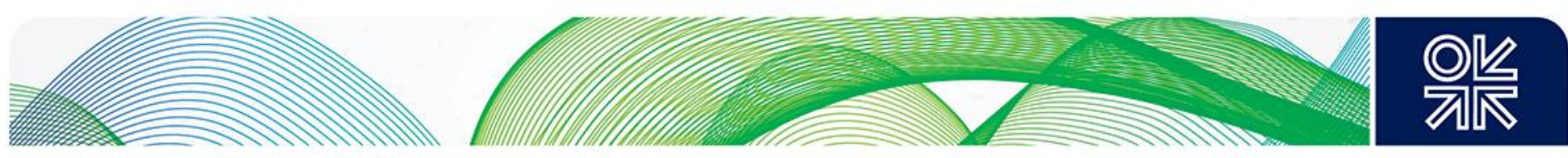

economy. In most countries, this has taken the form of indiscriminate and generous price subsidies for the supply of energy resources and the funding or part-funding of the required energy infrastructure. The pervasive use of energy price subsidies, their adverse financial impact and the policy options to address this issue have been extensively documented (examples, El-Katiri and Fatouh ${ }^{38}, 2015$, and IMF, 201739).

Furthermore, there is a misperception among some energy policy decision makers that the development of oil and gas activities would have a direct positive labour employment impact on the economy. Therefore, 'attractive' or put more plainly, subsidised energy prices should be encouraged. This ignores the fact that, except for the construction phase, most oil and gas projects are capitalintensive rather than labour-intensive. Even the production of petrochemicals and fertilisers follow the same capital-intensive pattern unless there is a well-developed downstream integration of these products within the economy with direct linkages to a series of smaller industries.

In the late 1970s and early 1980s, when it started developing its natural gas industry, Egypt followed the same pattern of energy price subsidies as in a number of other countries in the region and beyond. The financial burden of subsidies was manageable then due to a relatively small gas consumption. But new gas discoveries and a significant increase in Egypt's indigenous production of natural gas triggered a booming demand for gas. As a result, the continuous subsidisation (including cross-subsidisation) of domestic gas prices became financially unsustainable and demand ended up exceeding the indigenous natural gas production.

Faced with a mounting shortage of natural gas supplies, the Egyptian government decided to opt for LNG imports, increased the use of mazut (fuel oil) in the power sector and, in 2014, undertook a substantial upward adjustment of domestic natural gas prices, especially for gas use by the cement and metal industries. A 2014 prime ministerial decree increased the domestic gas prices to end-users as presented in the following table:

Table 3: Egypt: Domestic End-user Gas Prices (\$/MMBtu)
\begin{tabular}{|l|c|c|}
\hline Industry & 2014 PM Decree & $\mathbf{2 0 1 3}$ \\
\hline Cement ${ }^{40}$ & 8.0 & 3.0 \\
\hline $\begin{array}{l}\text { Iron \& steel; aluminium; copper; } \\
\text { ceramics; glass }\end{array}$ & 7.0 & 3.0 \\
\hline $\begin{array}{l}\text { Food; textiles; medicines; } \\
\text { engineering; bricks; other industries }\end{array}$ & 5.0 & $1.25\left(^{*}\right)$ \\
\hline Fertilisers \& petrochemicals & $4.5\left(^{* *}\right)$ & 3.0 \\
\hline Power & 3.0 & 1.25 \\
\hline
\end{tabular}

$\left({ }^{*}\right):$ Power and non-energy intensive industries

$\left({ }^{* *}\right)$ : \$4.5/MMBtu 'or according to the agreed contract's gas pricing formula'

Sources: Prime Minister's decree no. 1162 of 2014 and Aissaoui (2013).

Industry complained about these gas price increases and the payment terms for gas purchases. At the end of 2017, industry representatives raised these issues with members of the Egyptian parliament. Consequently, the Industry Committee of the House of Representatives submitted a memorandum to the Minister of Petroleum and Mineral Resources regarding these matters. Although

\footnotetext{
${ }^{38}$ Bassam, F. and El-Katiri, L. (2015). 'A Brief Political Economy of Energy Subsidies in the Middle East and North Africa', Oxford Institute for Energy Studies, MEP 11, February.

${ }^{39}$ IMF (2017), 'If Not Now, When? Energy Price Reform in Arab Countries', Rabat, Morocco, April. http://www.imf.org/en/Publications/Policy-Papers/lssues/2017/06/13/if-not-now-when-energy-price-reform-in-arab-countries. ${ }^{40}$ As indicated below in this demand section, cement plants have switched to coal. It is estimated that only one small stateowned plant is still using natural gas as a fuel.
} 

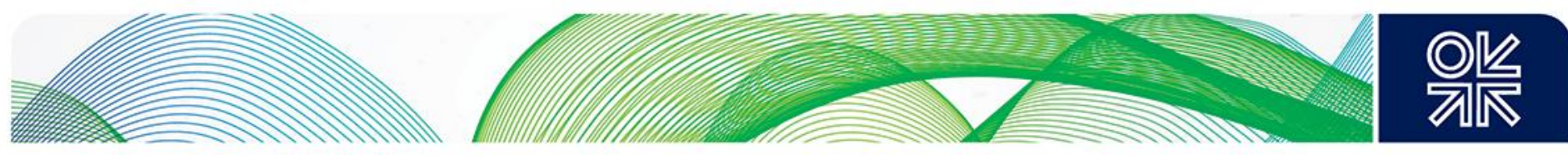

no official announcement was made in relation to these demands from industry, it is reported that the ministry is unlikely to consider any gas price reduction. But it was announced that the government, through EGAS, would consider more flexible payment terms. ${ }^{41}$

Subsidized gas supplies to the power sector and the petrochemical industry (including fertilisers) present financial challenges for the government, given the high cost of new offshore indigenous gas supplies (see Table 2), and the fact that these large users represent over 70 per cent of total domestic gas use and could continue to account for the bulk of Egypt's future gas consumption.

Although, LNG imports are being reduced and are expected to stop by the end of 2018 or beginning of 2019, they are still part of the gas supply mix being consumed in Egypt. At present, the approximate weighted average end-user price of gas for all consuming sectors is estimated to be close to $\$ 4 / \mathrm{MMBtu}$. This is to be contrasted with the prices of new indigenous gas supplies and LNG imports that could be well above $\$ 4 / \mathrm{MMBtu}$. It should be noted that, as per the upstream agreements, the government of Egypt gets a share of the gas produced by the IOCs free of charge. However, when estimating the weighted average cost of gas supply (and the resulting subsidy level), this volume of gas should not be valued at $\$ 0$ (zero)/MMBtu, but rather at its opportunity cost.

In order to make more gas supplies available, the government has allowed private entities to import directly their own gas needs. The new domestic gas market regulatory framework and its executive regulations are expected to clarify at least some of the relevant terms and conditions for such direct procurement options (see also subsection on sector regulation). Although some import licences have been granted to a small number of private entities and these authorisations have preceded the promulgation of the new gas market regulatory law, industries have been reluctant to import LNG, which in some cases would cost them much more than the currently subsidised indigenous gas supplies.

There has not been any clear indication of whether the government will introduce further gas price adjustments in the next fiscal year. The Ministry of Petroleum and Mineral Resources continues to make it clear that energy price subsidies remain a key challenging issue to address and it pointed out that 'when subsidy cuts were implemented, consumption decreased and renewable energy became more feasible.' 42 Thus, further price subsidy reform and adjustments, albeit gradual, should be expected and will be one of the driving factors affecting future gas demand growth. It should be pointed out that natural gas price subsidies have been reduced considerably in recent years. According to the International Energy Agency (IEA), in 2016 they accounted for less than three per cent of total energy subsidies, but they were estimated at a not insignificant $\$ 300$ million in an economy that is severely constrained financially. ${ }^{43}$

\section{Trends in gas demand growth}

The consumption of natural gas in Egypt increased significantly over the last two decades. It grew at a CAGR of seven per cent. Between 1996 and 2016, domestic natural gas consumption recorded an almost four-fold increase from 13 billion cubic meters $(\mathrm{Bcm})$ to about $50 \mathrm{Bcm}$. As shown in the figure below, the largest growth segment is the power sector. It is followed by the energy sector's own use and industries, including the non-energy use of natural gas as a feedstock in fertiliser and other petrochemical plants. A breakdown of the natural gas demand structure for 2016 is presented in the chart that follows.

\footnotetext{
${ }^{41}$ Egypt Oil \& Gas (2018), 'EGAS Offers Flexible Payment Terms on Natural Gas Supply Contracts', 19 February. http://egyptoil-gas.com/news/egas-offers-flexible-payment-terms-on-natural-gas-supply-contracts/.

${ }^{42}$ Daily News Egypt (2018). 'Subsidy reform is challenging for developing countries: El-Molla', 12 February.

https://dailynewsegypt.com/2018/02/12/subsidy-reform-challenging-developing-countries-el-molla/.

${ }^{43}$ IEA (2018), 'Energy Subsidies', https://www.iea.org/statistics/resources/energysubsidies/.
} 

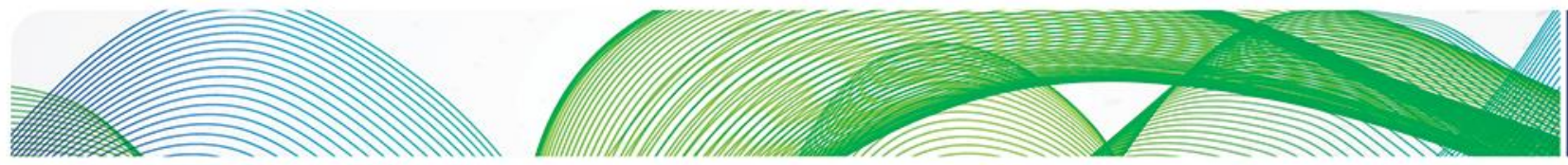

Figure 4: Egypt Natural Gas Consumption by Sector 1996-2016

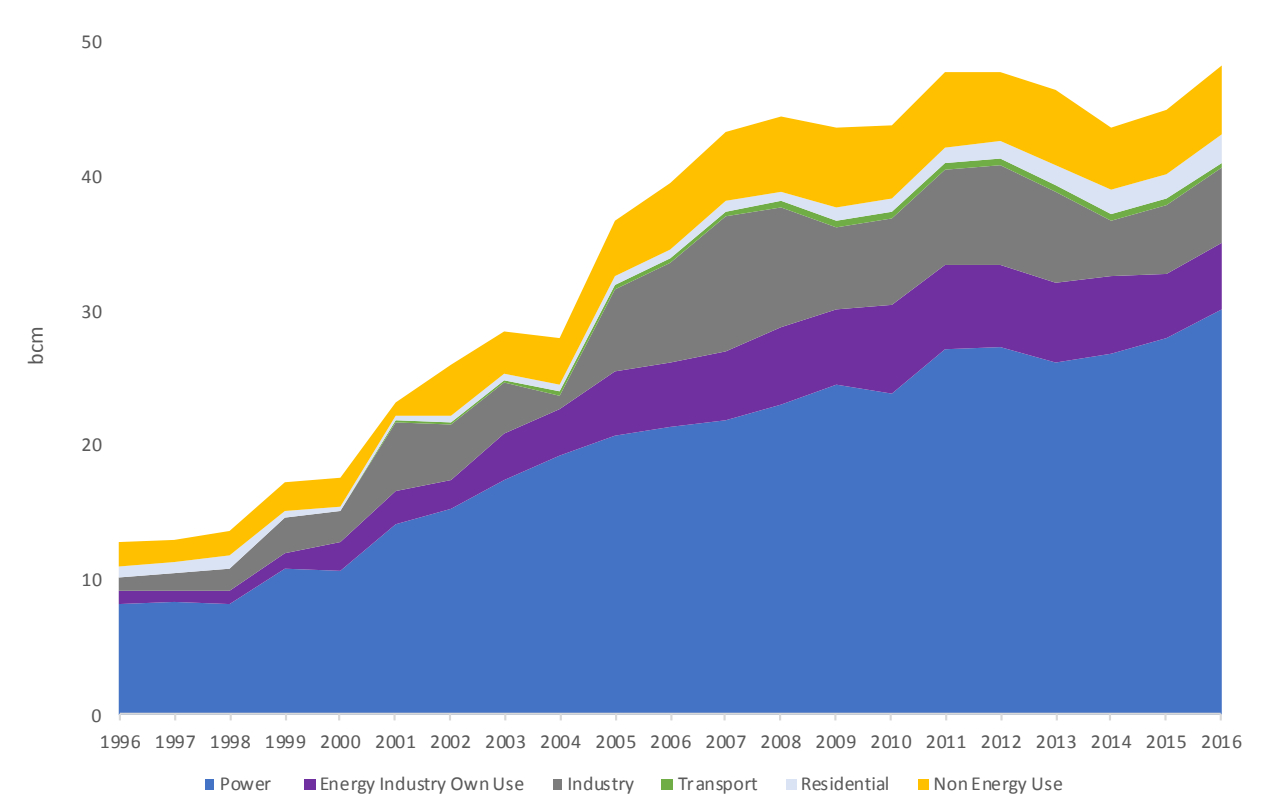

Source: IEA (2017).

Figure 5: Share of Gas Consumption by Sector (2016)

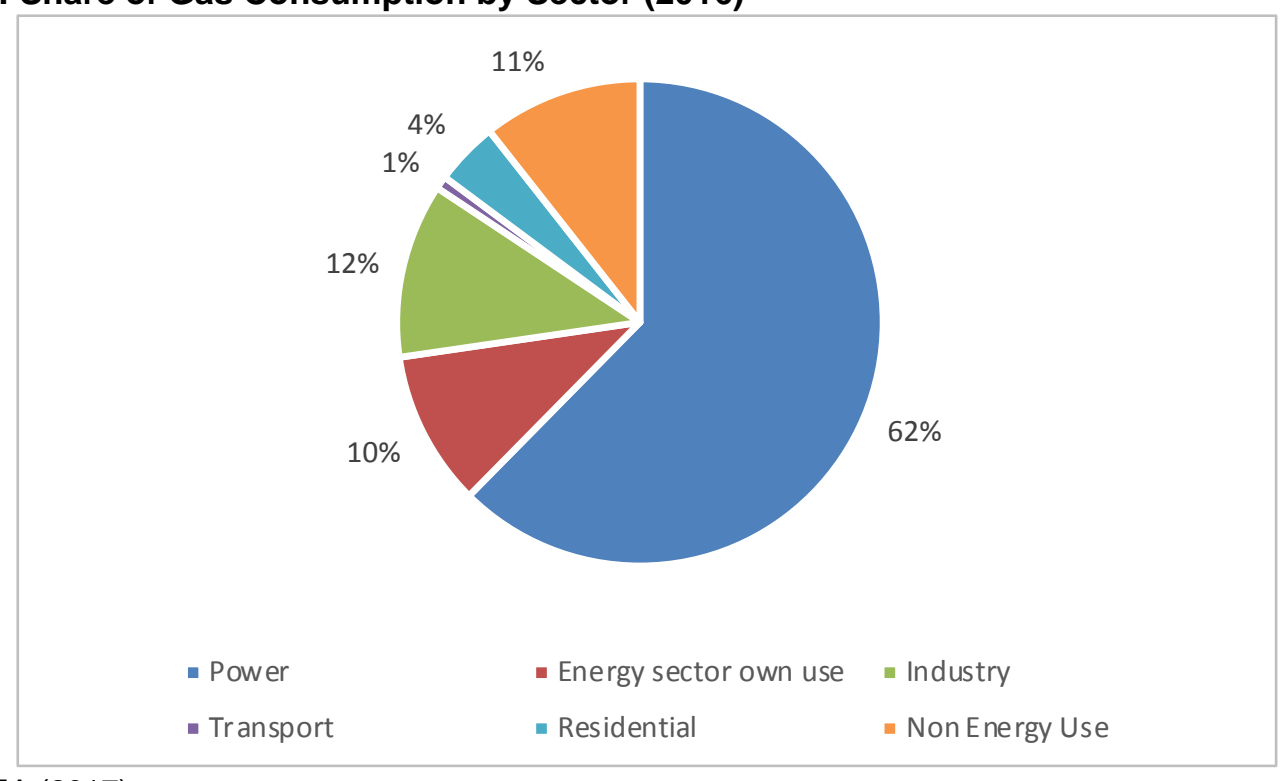

Source: IEA (2017).

It is important to examine the dynamics of the existing and potential future structure of each of these large consumers of natural gas, especially gas use to generate electricity, in order to present a view on the future movement of domestic gas demand in Egypt. 

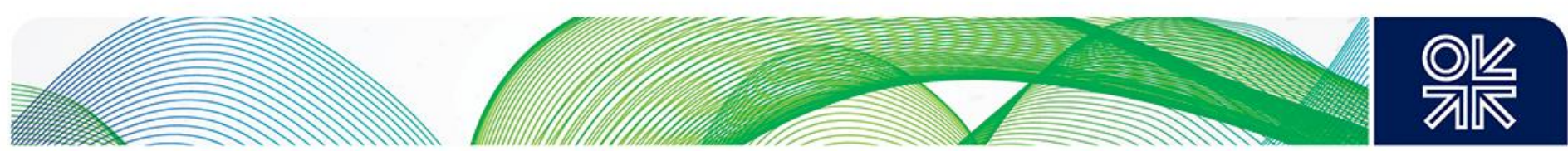

\section{Power}

Despite all the announced plans to diversify the mix of energy sources to produce electricity, natural gas is expected to remain the main fuel for Egypt's electricity generation for at least the next ten years. At present, this sector consumes $30 \mathrm{Bcm}$ of gas annually and accounts for over 60 per cent of the country's total gas use. It should be pointed out also that this level of gas consumption reflects a repressed demand constrained by the limited availability of indigenous gas supplies, as highlighted previously. The same applies to other gas consuming sectors of the economy which were supplyrationed, or had to switch to other fuels altogether, as priority of gas supply is given to the power sector. Thus, an increase in indigenous gas supplies could be mainly absorbed by gas-fired power plants. Nevertheless, the growth rate of gas use by the power sector and other sectors will depend on the impact of future increases of domestic gas prices and electricity tariffs, the speed of diversification of the country's energy mix, and Egypt's economic recovery pace.

In 2016, it was reported that Egypt had a total installed power capacity of about $39 \mathrm{GW}$. Thermal power plants represent 90 per cent of this total, with the rest covered by hydro and renewable energy (solar and wind) power plants. A 40 per cent increase of this capacity will take place by the end of 2018 with the completion of the more efficient 14.4 GW combined cycle gas turbine (CCGT) complexes that are currently being built in three locations, Beni Suef, Brulus, and the New Administrative Capital. It should be noted, however, that the Ministry of Electricity and Renewable Energy is also planning to gradually retire old and inefficient power units. For thermal power plants, the government is targeting a 20 per cent fuel efficiency improvement through the use of mainly CCGT units to generate electricity output. This measure should further reduce the sector's use of gas.

With an installed power capacity expected to reach about $60 \mathrm{GW}$ by the end of this decade, Egypt will not only have an adequate reserve margin, but will also have excess generation capacity. In fact, the Ministry of Electricity and Renewable Energy is reported to have postponed some generation projects initially planned for the current five-year economic development plan (2017-2022) and is presently focusing on the reduction of transmission losses and grid improvement projects.

According to announced government policy, the surplus of generation capacity will be dedicated to an electricity export programme targeting neighbouring countries in Africa (Sudan and Libya) and the Middle East (Jordan and Saudi Arabia). The details of this programme and the commercial viability of higher levels of electricity exports are not known. The government has also indicated that the surplus capacity could be used by new seawater desalination plants (or possibly combined power and seawater desalination systems), an area that the government is more likely to focus on given Egypt's critical water supply situation.

Egypt's future natural gas balance outlook over the next ten years will very much depend on how the demand for gas by the power sector evolves. Therefore, it is important to identify the main segments of the country's electricity consumption and how they could affect future electricity demand in the medium to long-term. As illustrated in the chart below, the residential sector accounted for almost half of all the electricity sold during the fiscal year 2015/2016. The second and third largest purchasers of electricity are the industrial and commercial sectors, respectively. These three sectors together consumed over 80 per cent of all the electricity sold in Egypt. 

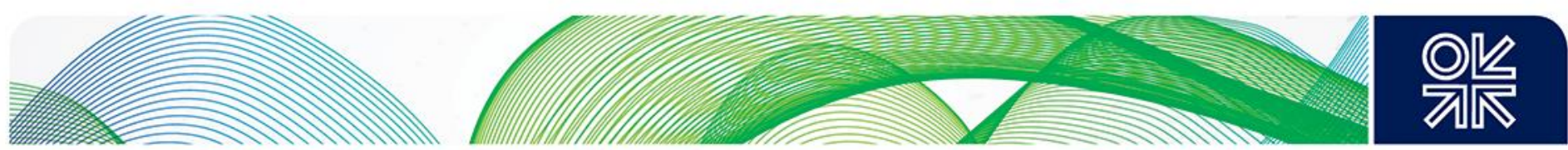

Figure 6: Egypt Total Electricity Sold by Category (2015/2016)

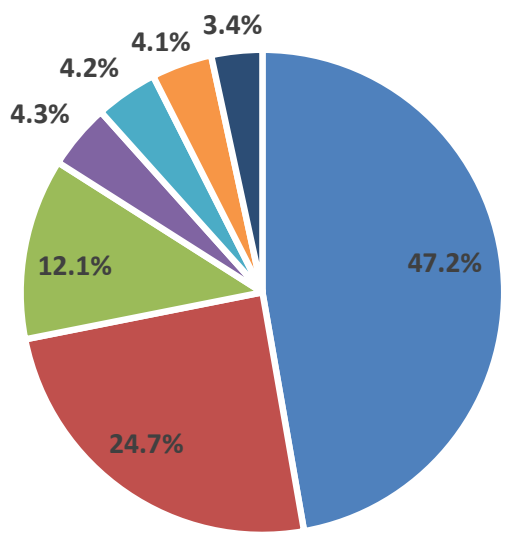

- Residential - Industry - Commercial \& Other - Agriculture - Utilities - Government Entities - Public Lighting

Source: Egyptian Electricity Holding Company (2017).

It is the residential sector that needs attention first. In 2015/2016, it absorbed almost 50 per cent of the electricity purchased. How will the consumption pattern of residential users change over the next five to ten years? This will depend on a number of factors, including population growth, household purchasing power, energy price elasticities (especially following the price subsidy reform), and conservation/efficiency/demand management efforts. The Ministry of Electricity and Renewable Energy has formulated a plan to improve energy efficiency, including non-price initiatives such as the use of LED bulbs. But, in order to have a significant energy saving/efficiency impact, price adjustment measures remain unavoidable. Electricity tariffs have already been raised, but further and sustained adjustments will be needed to reduce and, eventually, remove subsidies.

In February 2018, as part of the government's commitment to reform energy prices by removing subsidies and upwardly adjusting electricity tariffs at the beginning of each fiscal year, the Minister of Electricity and Renewable Energy announced that electricity tariffs will be increased at the beginning of next fiscal year (1 July 2018). In April 2018, the government announced that it is planning to reduce electricity subsidies by almost 50 per cent. ${ }^{44}$

Another key aspect that needs to be highlighted is the fact that electricity suppliers are presently faced with huge unpaid bills that are not easy to collect. In 2017, electricity distribution companies were owed close to $\$ 2$ billion, mainly from government entities and public agencies. This resulted in the power sector being unable to pay for all the fuel supplies it had purchased. This has a severely constraining knock-on effect on the finances of the Ministry of Petroleum and Mineral Resources which has to make regular payments to gas producers (IOCs).

As indicated above, higher electricity tariffs are required to reduce the subsidy level, but this would worsen the debt levels of the electricity consuming entities, unless radical changes are adopted for the reform of energy prices/tariffs and payments/collections along the whole fuel-to-power chain. Some of these changes are already taking place, like the replacement of old meters and the nationwide introduction of pre-payment meters.

This situation is not specific to Egypt, it is an unfortunate characteristic of a lot of economies burdened by the persistent presence of energy price subsidies. However, the Egyptian government seems

${ }^{44}$ Egypt Oil \& Gas (2018). 'Egypt Plans Energy Subsidies Reduction', 10 April. http://egyptoil-gas.com/news/egypt-plansenergy-subsidies-reduction/. 

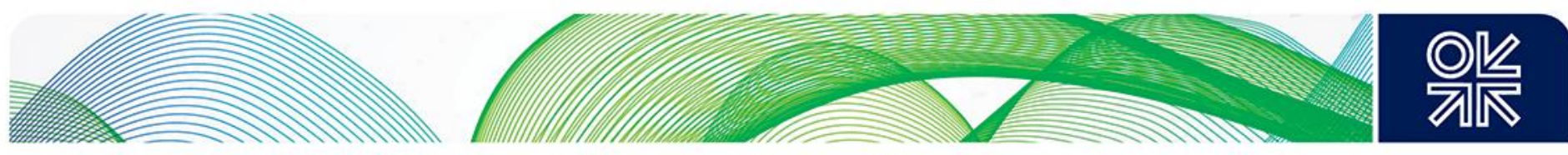

determined to address this subsidy issue. The Ministry of Electricity and Renewable Energy announced, in February 2018, that the government is planning to remove all electricity subsidies by 2020/2021. ${ }^{45}$ This could be a challenging target to implement, especially for residential users, and to a certain extent for small commercial consumers, but it shows the determination of the government to tackle this vexing subsidy issue. The process of complete removal of residential and commercial electricity price subsidies may take longer than planned. It is likely to take place gradually and will affect customers with the highest levels of consumption first.

For industry, the second largest category of electricity consumers, the sustainability of higher electricity tariffs will depend on the impact of energy costs on the prices of their final products and their ability to pass on the cost increases. Initially, higher electricity tariffs could lead to inflationary tendencies. In the longer run, it will probably result in a restructuring of these industries with only the most energy-efficient and competitive industries being able to adjust to new energy prices. This process of adjustment may reflect theoretical principles, but the reality on the ground may force such adjustments. The Egyptian government can no longer afford to finance large energy price subsidies, especially for industry, and seems committed to tackle the problem of energy price subsidies.

Based on the government's commitment and strong will to reform the energy sector and the policy decisions that have been taken so far, it is likely that electricity tariffs will continue to increase gradually every year, with special schemes to protect low-income households being adopted. Electricity tariff adjustments, efficiency measures and the push for development of renewable energy sources ${ }^{46}$ are expected to affect gradually the rate of growth of electricity demand and consequently future natural gas use.

Therefore, it is suggested that gas demand for the power sector over the next ten years could grow at a slower pace compared to the last twenty years. However, it should be pointed out that this slower growth rate will only take place when all the phases of the new 14.4 GW CCGT complexes are fully operational. Thus, electricity generation from these large new power complexes will, initially, result in a sharp jump in gas demand profile over the $2018 / 2019$ period and then will grow at a moderate rate.

\section{Industry}

Energy-intensive industries have the second largest share of natural gas use in Egypt. These include the steel and cement industries. Other industries include textiles, food, ceramics and other light industries. Steel and cement production are quite important for the Egyptian economy, more specifically for the construction and building sector and for the generation of export revenue. Both industries have seen their allocation of gas supply reduced to meet the needs of the power sector. At the same time, the price of gas supplies to steel and cement factories has increased significantly.

Egypt has the largest cement production capacity in the Middle East and North African region and the world's $12^{\text {th }}$ largest cement industry. Nevertheless, Egypt's natural gas supply shortage and new high gas prices forced its cement industry to reduce considerably its cement production and to switch to a different fuel, like coal or a mix of fuels. As a result, this industry's current natural gas consumption represents just a small part of total gas consumption. The use of coal by cement factories was approved by the government in 2014 with a proviso from the Ministry of Environment that required that coal licences would be granted subject to the formulation of a mandatory greenhouse gases (GHG) reduction plan. ${ }^{47}$ Alternative fuels, such as energy generated from waste, have been proposed as substitutes for fossil fuels, especially for more polluting fuels such as coal and heavy fuel oil. ${ }^{48} \mathrm{It}$ remains to be seen whether such alternatives will be adopted. The price of the fuel remains the key

\footnotetext{
${ }^{45}$ Daily News Egypt (2018). 'Energy subsidies will be zero by FY 2020/2021: Shaker', 22 February. https://dailynewsegypt.com/2018/02/22/energy-subsidies-will-zero-fy-2020-2021-shaker/.

${ }^{46} \mathrm{~A}$ new improved renewable energy feed-in tariff model is expected to be issued in July 2018 to encourage production of electricity from renewable sources. But it is not clear yet what it would cover.

${ }^{47}$ IFC (2016). 'Alternative Fuels for Egypt's Cement Industry'. https://www.ifc.org/wps/wcm/connect/aaa24840-cb94-40c6-9ab1bb0252a6d2fb/IFC+AFR+Report+_+Web_+1-11-2016.pdf?MOD=AJPERES.

${ }^{48}$ IFC (2016). 'Alternative Fuels for Egypt's Cement Industry'.
} 

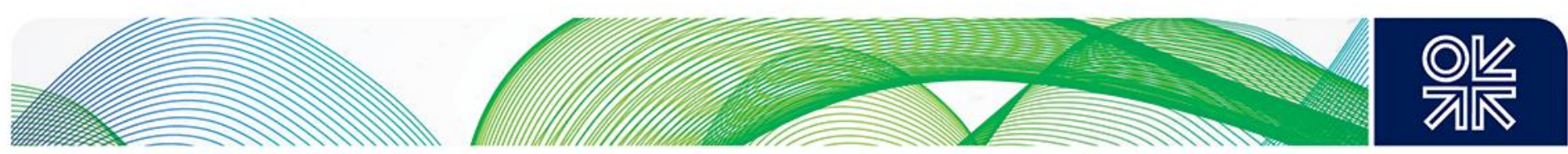

driving factor for the selection of fuel(s) for the cement industry, as well as for other energy intensive industries.

For a long period of time, the domestic price of gas to the cement industry was heavily subsidized and resulted in a series of cement projects being planned and developed. But the sharp drop in gas supply availability, and the decision to import more expensive gas, pushed the Egyptian government to increase domestic gas prices. The latest price adjustment increased the price for gas supplies to cement plants to $\$ 8 / \mathrm{MMBtu}$ (see Table 3). A price level that has a significantly adverse impact on cement production costs and that has led the majority of cement plants to switch to coal use or cheaper fuel alternatives. This is even more critical with the present, fierce international competition and capacity surpluses in international cement markets.

The price pressure is quite similar for the Egyptian steel industry, which is now facing a higher domestic gas price of $\$ 7 / \mathrm{MMBtu}$ for the domestic procurement of gas supplies. Natural gas is used as a reducing agent in the process of direct reduction of iron ore (DRI) and as a fuel for the production of electricity. Therefore, the future gas demand levels of this other energy-intensive industry will depend on inter-fuel substitution economics, especially between natural gas and coal. As with the cement industry, the potential increase of coal use by Egypt's energy intensive industries will have an adverse environmental impact if GHG mitigation measures are not considered.

Under the current higher domestic gas pricing regime, the clear indication from the government that gas prices will not be reduced and the fact that most of the cement plants have already switched to other fuels, gas demand by the cement industry is not expected to grow at the same speed as during the previous decades. Its growth of gas use would be low at best. The steel and other industries are also unlikely to obtain price cuts or subsidies and will have to rely on a mix of fuels and efficiency measures. It should be noted, however, that given the local oligopoly position of some of these industries, increased fuel costs could be more easily absorbed and in fact passed on to domestic consumers of their products in the short to medium term. Nonetheless, for industries completely exposed to exports and international competition, higher gas prices will require structural business adjustments and probably a more diversified energy mix. As a result, gas demand growth by the energy-intensive industry as a whole will be limited.

\section{Petrochemicals}

The development of a petrochemicals industry, including the production of fertilisers, has been one of the key strategic decisions taken by the Egyptian government to monetise Egypt's hydrocarbon resources in order to stimulate 'economic development and growth'. The strategic planning process started in 2001 with the formulation of a 20 -year master plan for the petrochemicals industry. It was followed by the creation, in 2002, of the Egyptian Petrochemicals Holding Company (Echem) to support the implementation of this long-term plan. The multi-phase master plan's total cost is estimated at $\$ 20$ billion and is expected to include the development of 14 petrochemical complexes. ${ }^{49}$

The main component of natural gas - methane - is used as a feedstock ${ }^{50}$ for the production of nitrogenous fertilisers and methanol. Egypt is Africa's largest fertiliser producer and it is also a large fertiliser exporter. There are, at the moment, several fertiliser plants in operation and only one methanol plant supplying both the domestic and export markets. The fertiliser industry is dominated by the Abu Qir Fertilizers Company (AFC), which is the largest nitrogenous fertiliser producer in Egypt. The AFC complex, located in the coastal town of Abu Qir near Alexandria, accounts for about 70 per cent of Egypt's nitrogenous fertilisers output.

New project expansions have been commissioned in recent years or are soon to be commissioned. These are the second fertiliser unit of the Misr Fertilizers Production Company's plant (MOPCO 2)

\footnotetext{
${ }^{49}$ Echem (2018). 'Egyptian Petrochemicals Industry: A Prospect for the Future', Echem website, echem-eg.com.

http://www.echem-eg.com/en/MasterPlan/gallery-photogallery_pics-pic_65.pdf

${ }^{50}$ Some of the gas is also used as a fuel to generate energy.
} 

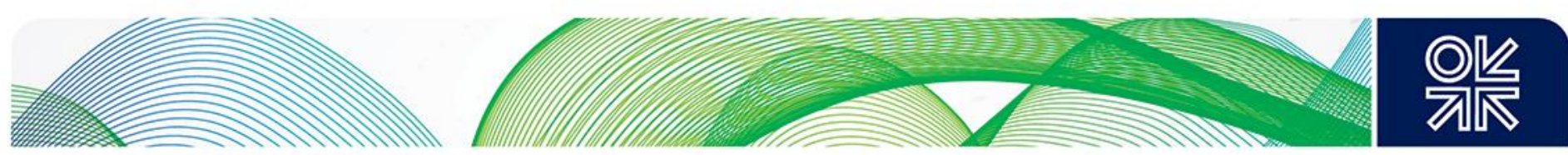

located in Damietta, near Port Said on the Mediterranean coast, and also the second unit of the Egyptian Chemicals Industries Company's plant (KIMA 2) sited in Aswan, in Upper Egypt. MOPCO 2 was commissioned in December 2016 and KIMA 2 is scheduled to be commissioned by the end of 2018.

Egypt's methanol production capacity is presently limited to the Egyptian Methanex Methanol Company (E-Methanex) plant located in Damietta. According to the country's long-term petrochemicals master plan, there is a plan for the development of a second methanol plant, but the status of such project has yet to be confirmed.

The latest data available on domestic gas consumption shows that in 2015 and 2016, about $5 \mathrm{Bcm}$ of natural gas was consumed annually for the production of these bulk chemicals. This gas use accounted for about 10 per cent of the country's domestic gas use. But, it should be pointed out that until very recently, the delivery of gas supplies to petrochemical plants was severely rationed. Therefore, under favourable price conditions, gas use by the petrochemical industry could potentially increase its share of natural gas demand.

The discovery and development of new indigenous sources of natural gas, such as Zohr, have fuelled a lot of interest and enthusiasm on the part of the local petrochemical industry which is asking for a share of the gas supplies to be re-allocated from the power sector to their industry. It is also requesting a reduction of the domestic gas prices of these supplies. According to the General Authority for Investment and Free Zones (GAFI), the petrochemicals industry contributed about three per cent of Egypt's gross domestic product and the government is keen to see this share increasing. Recent statements by the Minister of Petroleum and Mineral Resources announced that the bulk of the gas surplus will be directed to develop the petrochemical industry. ${ }^{51}$

The achievement of such objectives will depend on the size of the gas surplus available, how long it will last and, importantly, the expected end-user prices of gas supplies to the petrochemical industry. The commercial viability of producing bulk petrochemical commodities, such as fertilisers and methanol, depends on the cost competitiveness of feedstock supplies. With prices of new offshore natural gas supplies that could reach up to about $\$ 6$ per MMBtu under the current gas pricing mechanism (see Table 2) before transportation and other charges, the economics of new methanebased chemical projects could be fragile.

This challenging situation could perhaps be addressed by considering the integration of the bulk chemicals produced with the production of other less gas feedstock-intensive chemicals that would add value and lessen the gas price sensitivity. However, this would take a longer time-horizon and the financing of additional large investments, among other things. Older fertiliser plants with their amortised infrastructure should have a better feedstock price flexibility than new plants. But some of these old plants may need to be revamped first.

Therefore, for the purpose of this paper's time horizon, it is assumed that Egypt's natural gas (methane) use by fertiliser and methanol plants will be limited to existing and currently underconstruction projects.

\section{Energy sector's own use}

The energy sector, especially the oil and gas industry, is a large consumer of natural gas for its own operations. Over the last ten years, the level of its gas use has been about constant. This reflects the relative slowdown in hydrocarbon activities during this period, but also the economic activity downturn that followed the revolution. With the relaunch of upstream operations and economic activities in Egypt, this category of gas use is expected to record a positive growth rate in the next ten years.

\footnotetext{
${ }^{51}$ Daily News Egypt (2017). 'Cost of LNG imports during current fiscal year amount to \$1.8bn: Minister of Petroleum', 18 September. https://dailynewsegypt.com/2017/09/18/cost-Ing-imports-current-fiscal-year-amount-1-8bn-minister-petroleum/.
} 

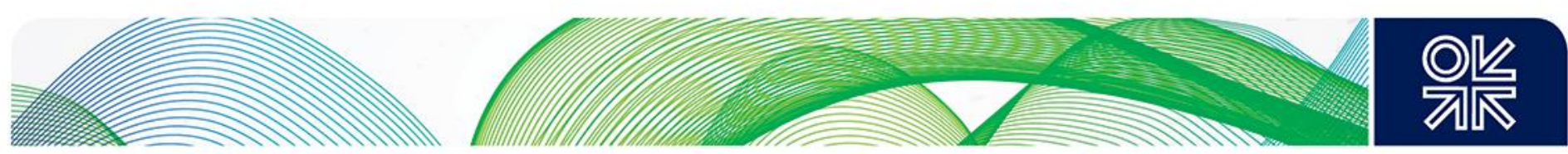

\section{Other sectors}

The sectors covered in the previous subsections represent about 95 per cent of the current total natural gas use by the domestic market. The rest is consumed by the residential (about four per cent) and transportation (about one per cent) sectors. The government is keen to expand the use of natural gas in the residential sector. With a CAGR of more than 10 per cent between 2006 and 2016, the residential sector is the fastest growing segment of natural gas use in Egypt, though having consumed only about two Bcm annually over the last few years. The number of residential connections to gas rose from about half a million in the mid-1990s to over eight million connections in the first quarter of 2018, with the objective of reaching approximately 10 million connections by the end of 2018.

This rapid growth is the result of a strong government commitment to increase the penetration of natural gas in Egypt's residential sector and to reduce household use of LPG (butane), which is imported and supplied to households at heavily subsidised prices. Yet, the price of natural gas consumed by households is also heavily subsidised by the state at a price well below $\$ 3$ per MMBtu. But even this relatively low-price level is a challenge for low income households which, in addition to the cost of gas, also have to pay for the connection/installation cost, despite the payment flexibility and other incentives offered.

Residential users are supplied by local gas distribution companies which would find it commercially difficult to expand supply to this segment of the domestic gas market, unless significant economies of scale can be achieved through the supply to much larger customers (e.g. industries and power plants) in the same area. Therefore, the future growth of natural gas use by the residential sector will very much depend on the government's ability to continue supporting natural gas use by residential consumers. This could be envisaged in areas where there is existing or new development of natural gas infrastructure and more commercially attractive non-residential gas demand. Overall, residential gas demand growth will remain strong, but this demand will increase at a much slower pace than during the last ten years.

Egypt's other small natural gas consuming sector is transportation. In 2016, this sector consumed about half a Bcm of natural gas, which is a very limited use of a less polluting fuel in a country that suffers from severe pollution problems in its densely populated urban centres. Yet, it should be noted that Egypt started the planning of natural gas use in transportation several decades ago, initially to reduce the unabated growth of high cost imported liquid petroleum products and then to address the critical issue of urban pollution in Egypt's main cities, especially Cairo.

In Egypt's transportation sector, natural gas is used as compressed natural gas (CNG) to fuel mainly taxis, which account for 70 per cent of the country's gas-fuelled vehicles. The key driver that stimulated the initial growth of CNG use was the price differential between CNG and gasoline prices. The substantial CNG price increase that took place in recent years has reduced the savings that could potentially be made by converting a vehicle to natural gas. Other constraints such as conversion costs; availability of refuelling stations; refuelling time; and, limited distance covered could slow down the growth of natural gas use in transportation. Nonetheless, even if the government decides, for environmental reasons, to support the use of natural gas in transportation, especially for public transportation vehicles, the small volumes consumed will still have a relatively limited impact on Egypt's natural gas balance.

\section{Proposed ten-year gas demand profile}

Several factors are expected to influence the domestic demand for natural gas in Egypt in the next ten years. Among the key drivers of gas demand growth, in addition to the country's economic growth situation, are; future movement of domestic gas prices, especially for the power sector, and adequate availability of natural gas infrastructure capacity to meet existing and potential expansion of gas demand in new areas/regions. Alternative energy sources of electricity generation are expected to take longer than ten years to have a significant effect on the reduction of gas-fired generation and 

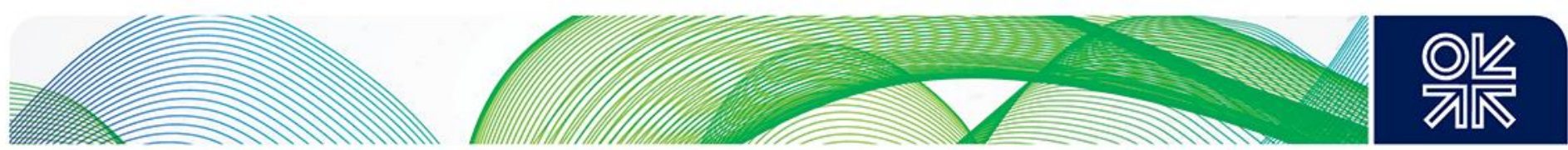

therefore on the total gas demand. Furthermore, the impact of the above main factors would be affected by the speed of reform of the whole energy sector, as the natural gas subsector cannot be looked at in isolation from other energy subsectors, especially the power sector and its gas use which plays an extremely dominant role in the country's natural gas balance.

The pace at which the new domestic gas market regulatory law will be implemented, as well as the role of the government in supporting/facilitating the implementation of this new regulatory framework, will be critical. It is clear that the full implementation of this new gas law will take at least ten years, when allowing for all the transitional phases envisaged (see section on sector regulation) and a realistic time-framework such market restructuring will require. Therefore, during the next ten years, Egypt's domestic gas demand profile is likely to reflect this transitional move towards a 'liberalised' domestic gas market. In the Egyptian context (or any other developing economy's context), the meaning of the words 'liberalised market', need to be treated with great caution as, for some, it means a market mimicking the gas markets of North Western Europe. When referring to gas market reform, it is understood that the market fundamentals remain the same, but that market conditions and the reform path and speed taken could differ significantly from one country to another.

The following proposed ten-year gas demand profile for Egypt draws on the previous sectoral gas demand reviews. Disaggregated data on existing and future gas demand by sector and subsector in Egypt is very limited or unavailable. Nevertheless, as indicated in the gas supply section, the purpose of this paper is not to produce gas market projections, but to identify key drivers, developments and challenges that may affect Egypt's natural gas balance and to propose a view on future gas balance profiles.

Figure 7: Proposed ten-year gas demand profile (Bcfd, averages)

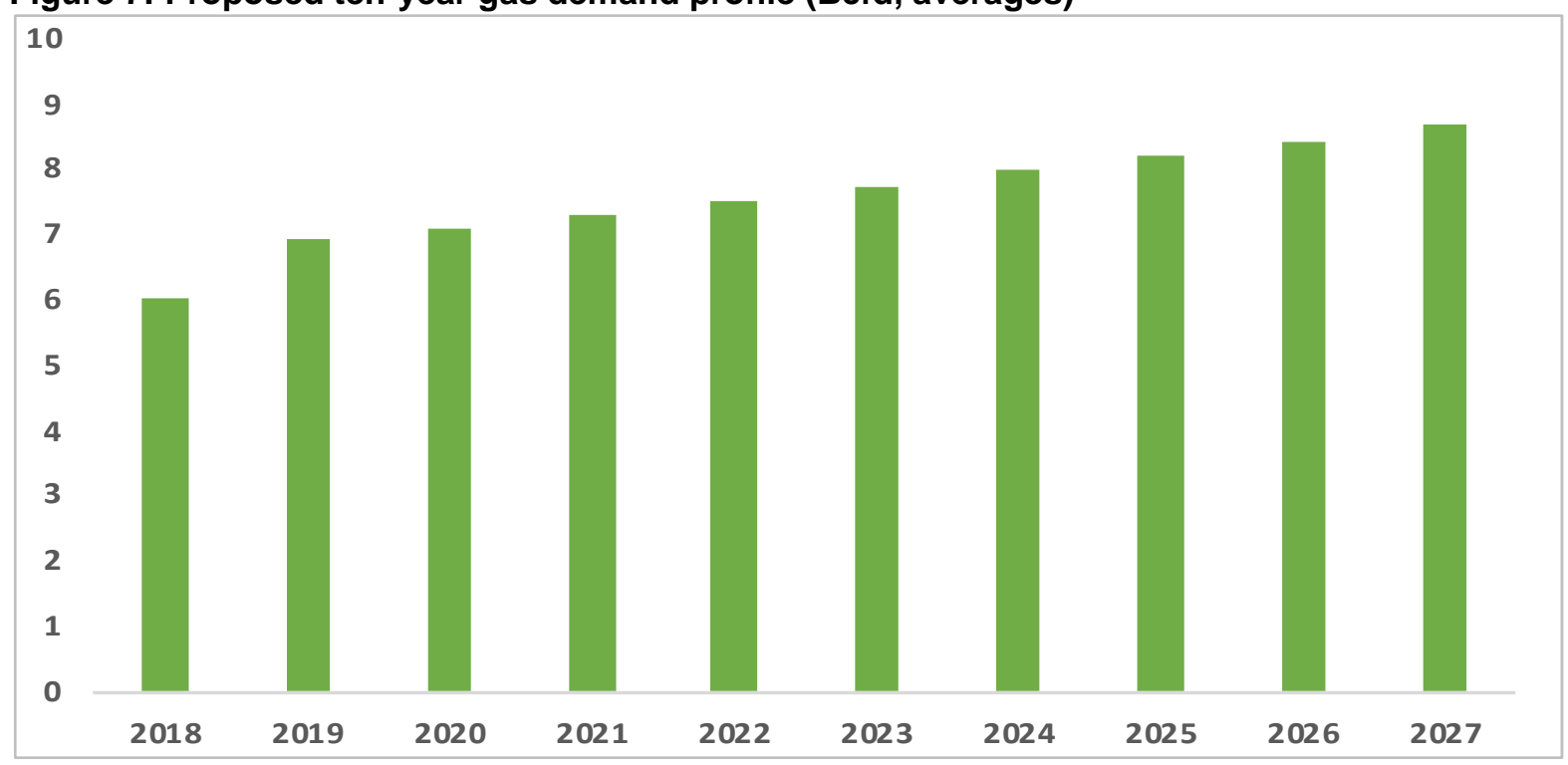

Source: author's estimation. 

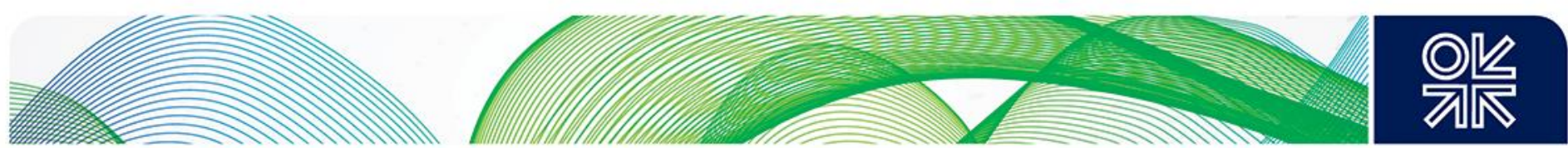

\section{Gas Balance \& Export Prospects}

\section{Gas balance}

A consolidation of the natural gas supply and demand profiles reviewed and presented in the previous two sections is shown in each of the following charts on Egypt's natural gas balance over the next ten years.

Figure 8: Gas balance - supply scenario A (Bcfd, averages)

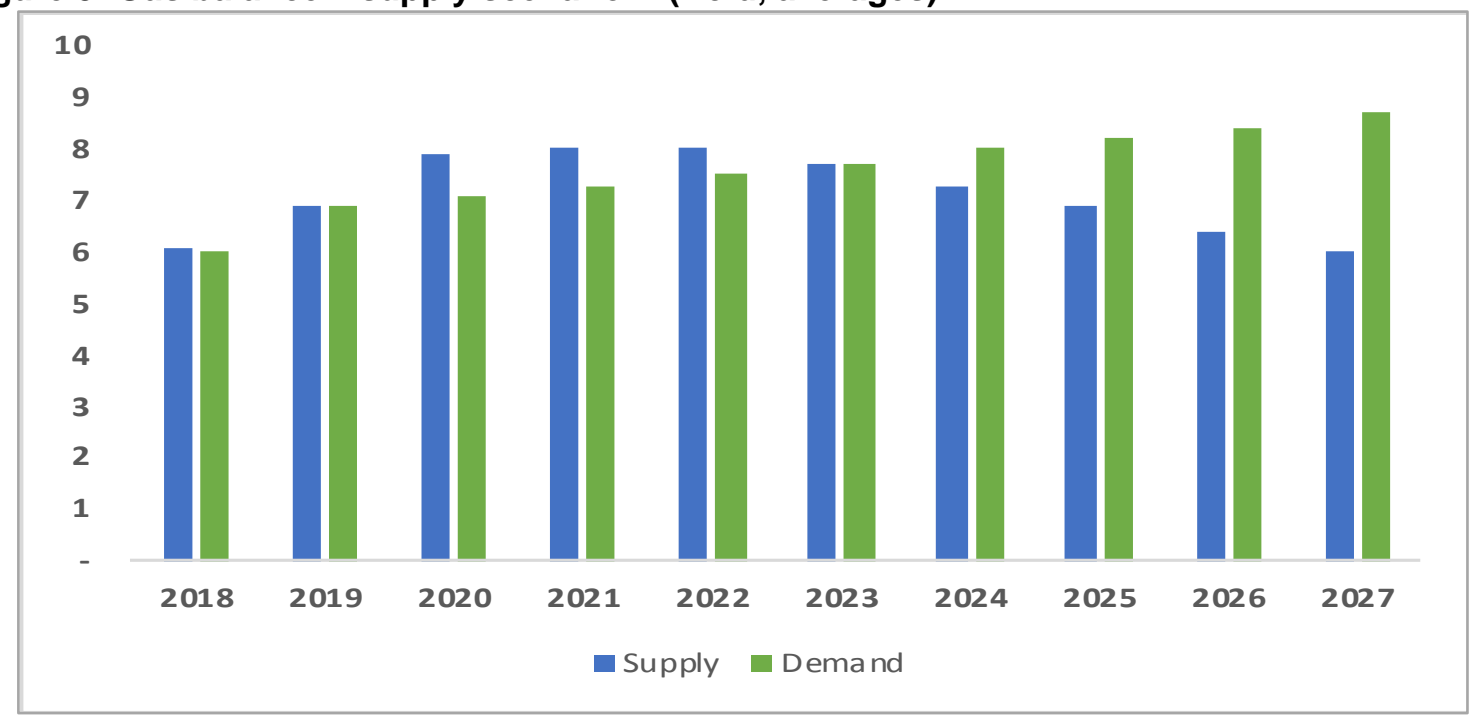

Source: author's estimation.

Figure 9: Gas balance - supply scenario B (Bcfd, averages)

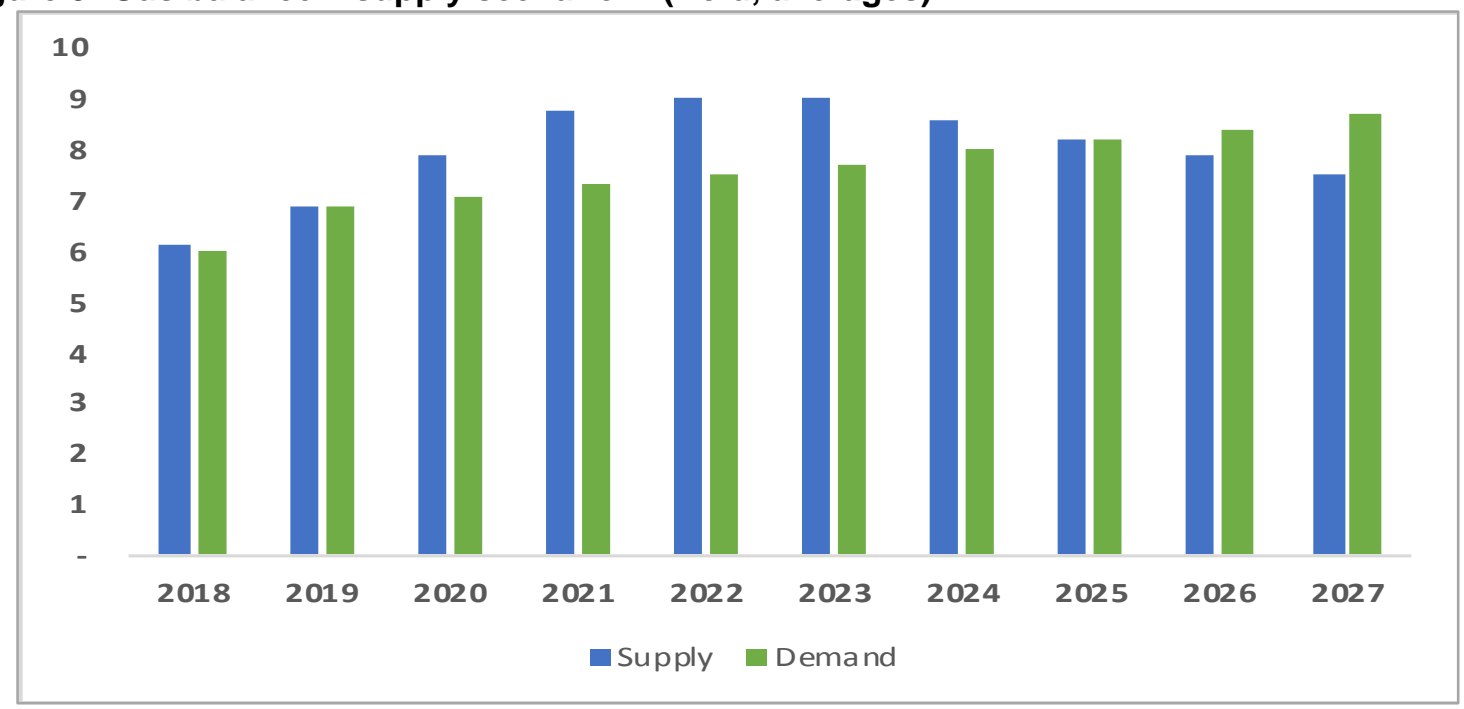

Source: author's estimation.

Scenario $A$, which is based on supplies from legacy producing fields and new gas fields that have just come on stream and/or are expected to start producing in the next few years, shows a gas supply surplus emerging by the end of this decade and reaching a maximum level of close to 1 Bcfd by 2020 . 

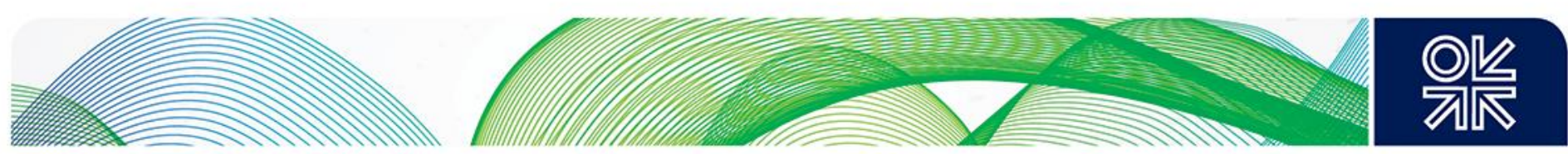

The potential surplus level would be sustained for only a few years before declining rapidly. But the country's domestic gas demand would be satisfied and there would be no requirements for LNG or gas pipeline imports until early 2024. Under this first scenario, the supply deficit increases significantly over time to a level of well over 2 Bcfd on average, close to the end of the ten-year horizon in 2027. It must be reiterated that this scenario is based on the assumption that no new discoveries and developments will be made in Egypt, other than the ones listed already in the section on natural gas supply developments.

Scenario B presents an optimistic or speculative supply side scenario by incorporating other new discoveries and developments assumed to come on-stream at the beginning of next decade and adding between 1 and $1.5 \mathrm{Bcfd}$ of incremental gas supply. The speculative assumption of additional gas supplies would increase the gas surplus to a maximum of $1.5 \mathrm{Bcfd}$ by 2021 and then the surplus would start declining until 2025. Then the balance would switch to a deficit situation and by 2027, the supply gap would be $1 \mathrm{Bcfd}$. As pointed out for Scenario A, the second scenario reflects current data and information available on future gas supply developments.

\section{Gas export prospects}

The proposed gas balance scenarios presented above suggest that, under these scenarios' assumptions, Egypt will be unable to regain its past natural gas export position (when it was exporting well above $10 \mathrm{Bcm}$ per year) until the beginning of next decade and this will last for far less than ten years. However, the government will have achieved its priority target of fulfilling the needs of its domestic gas market and stopping, or reducing significantly, natural gas imports and their relatively high financial costs. This achievement is an important one for Egypt's government and national economy and should not be underestimated by focusing on exports only.

The overall issue of how the government would wish to monetise its expanded natural gas resources and capture the rent would need to be looked at, subject to government's existing contractual export commitments. Should this rent be captured mainly through gas exports or through domestic monetization, or through an adequate combination of the two? If the domestic market offers attractive options, that is, if the relevant price netbacks are as remunerative as exports, and payments are not an issue, expanded domestic gas monetisation uses could be considered.

As indicated previously, the supply profiles shown in this paper may not necessarily reflect the fields' development plans agreed between Egypt's upstream regulatory authorities (or the entity(ies) performing this regulatory role) and international oil and gas companies, the reservoirs' performance, realistic implementation path, and other factors. Future annual or seasonal levels of natural gas exports would vary depending on the then prevailing international market conditions resulting in different annual and seasonal supply profile shapes. Because of the fundamental changes in international and Egyptian natural gas markets since the beginning of this decade, Egypt's government and its IOC partners could adopt a gas export strategy based on smaller volumes, leveraging seasonal export opportunities, more contractual flexibility, and different parties could be involved from the state and private sectors.

By the end of the next decade and beyond 2030, Egypt's energy portfolio could undergo some structural changes if efforts towards diversifying the country's energy mix, especially for the generation of electricity, are fast-tracked. As a result, some additional gas supplies could be released by the end of the next decade that could potentially be exported. But it remains to be seen whether more significant progress in these diversification efforts will attenuate the current high dependence on natural gas as a generating fuel in the power sector. 

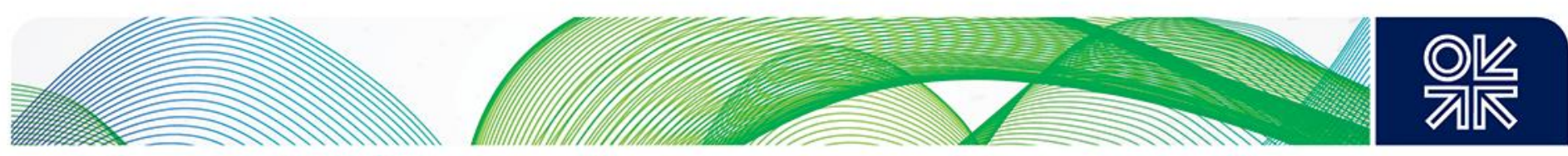

\section{Gas export 'Hub'}

Egypt holds a central position in East Mediterranean gas developments. It has a relatively large natural gas export infrastructure which is presently severely under-utilised. This infrastructure is by far the largest in the East Mediterranean area and consists of two LNG export plants and two crossborder gas pipelines with an overall gas export capacity of about $35 \mathrm{Bcm}^{52}$, well above Egypt's potential future gas export levels based on current data and information. New large indigenous gas discoveries could increase the potential for exports and thus improve the infrastructure's future rate of utilisation. It would take five to ten years before any new incremental supplies could be exported. At this stage, this alternative remains a speculative one.

A quicker option could be to use Egypt's LNG export facilities to liquefy and export gas supplies from existing and potential new East Mediterranean gas producers, namely Israel and Cyprus, and transform Egypt into a regional gas export 'hub'. Before exploring this option, it is important to clarify that the meaning of 'hub' in this context does not refer to gas trading hubs of mature and liquid gas markets, such as those of North Western Europe (see Heather, 2015). The hub in this paper simply relates to the country's physical natural gas export infrastructure mentioned above and the possibility that natural gas supplies within the East Mediterranean area could be processed and exported through this infrastructure.

Since the first gas discoveries were made in the Eastern Mediterranean and the relatively larger discoveries that followed, a few countries have been vying for the role of gas or energy hub. Initially, Cyprus proposed to develop an LNG export facility that would potentially liquefy its own gas from the Aphrodite field, as well as gas from Israel's offshore fields, and become a regional energy hub. ${ }^{53}$ Further north Turkey, which is already a key transit country for gas supplies from the former Soviet Union region to Europe, has also been considered as a possible Mediterranean energy hub. ${ }^{54}$

In the case of Egypt, the government has been promoting the country as a potential energy hub for the region to leverage not only its gas export infrastructure, but also its liquid hydrocarbon infrastructure (like the Sumed crude oil pipeline from the Gulf of Suez to the Mediterranean coast) and its existing and expanded power capacity and export interconnections. This regional energy hub project is part of the government's oil and gas modernisation programme and is supported by international organisations like the World Bank (see subsection on 'Energy Strategy \& Petroleum Sector Modernization Program'). With regard to natural gas, Egypt, with its substantially under-utilised gas export infrastructure, would be best positioned to become a regional hub for the aggregation of gas supplies from neighbouring gas producing sources and their exports as LNG from its Idku or Damietta-based LNG plants. A proposition that is being actively explored with one potential East Mediterranean source of new gas supply, Cyprus.

In 2016, the Egyptian and Cypriot governments signed a memorandum of understanding (MoU) to transport gas from Cyprus to Egypt for the local Egyptian market and for exports through the Egyptian liquefaction facilities. The gas would be transported through a direct pipeline from Cyprus to Egypt's coast. There was also the idea of sending Cypriot gas from the Aphrodite field via the Zohr offshore facilities, but the present capacity of the infrastructure would not be sufficient to handle additional supplies from Cyprus. This situation could change with Eni's discovery of the Calypso field in Cyprus. Depending on the size of the resources in place there, some integrated scheme with expanded infrastructure capacities could be considered, if commercially viable. However, at the moment, the focus seems to be on a direct pipeline from Cyprus to Egypt.

\footnotetext{
${ }^{52}$ Assuming that this total nameplate capacity is usable.

${ }^{53}$ Cyprus Mail (2016). 'Can Cyprus become a regional energy hub?', 11 September. http://cyprus-mail.com/2016/09/11/cancyprus-become-regional-energy-hub/.

${ }^{54}$ Hurriyet Daily News (2017). 'Turkey's dream of becoming an energy center at risk', 28 November.

http://www.hurriyetdailynews.com/opinion/erdal-saglam/turkeys-dream-of-becoming-an-energy-center-at-risk-123148.
} 

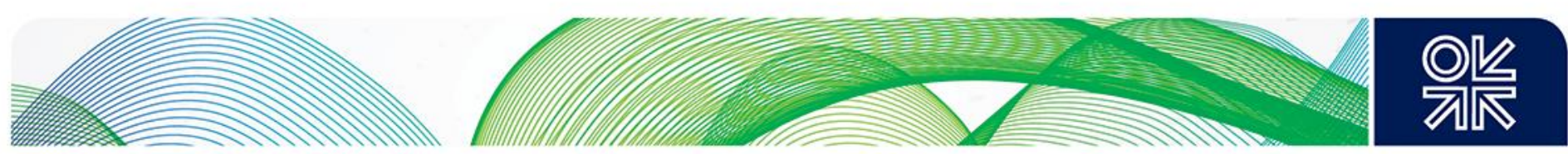

In May 2018, the Egyptian Ministry of Petroleum and Mineral Resources announced the planning of a gas pipeline from Cyprus' Aphrodite field to Egypt's LNG facilities. ${ }^{55}$ One key aspect which is not clear from these government announcements - in Cyprus and in Egypt - is the commercial viability of such an East Mediterranean gas pipeline project, especially if the gas from Cyprus is planned to be reexported.

Egypt's liquefaction infrastructure could also be utilised to export supplies from Israel's Tamar and Leviathan offshore fields. There were discussions to send supplies from the Tamar field to the Damietta LNG plant and gas from the Leviathan field to the Idku LNG facilities. ${ }^{56}$ More recently, Israel announced that a private Egyptian company - Dolphinus Holding - has signed two 10-year agreements with Noble Energy and Delek Drilling to import a total of about $64 \mathrm{Bcm}$ over a period of ten years. ${ }^{57}$ These imports are to be supplied with gas from the Tamar and Leviathan fields. The details of these agreements have not been made public and it is not clear whether the option of reexporting Israeli gas through Egypt's LNG export infrastructure would be considered or not, or how the gas would be transported to Egypt. But the same rationale applies to these potential gas pipeline projects between Israel and Egypt or Cyprus and Egypt. They have to be commercially viable.

The development of a regional gas export hub in Egypt would optimise the use of the country's gas export infrastructure and could help the monetisation of potentially stranded East Mediterranean natural gas resources. It would generate transportation and tolling revenues for the Egyptian economy, potentially increase gas supply availability for the Egyptian market, and would stimulate renewed investments in Egypt's hydrocarbon sector. However, in order to achieve such regional integration opportunities some formidable challenges would need to be overcome. These are not only the geopolitical problems and territorial disputes that make headline news. As indicated above, the other key obstacles to the development of a regional gas export project are the commercial viability of exporting gas from third party sources and the formulation of contractual arrangements and intergovernmental agreements that would be acceptable to all the parties. Focusing on the commercial aspects only shows that, under present international gas market conditions, re-exporting Cypriot or Israeli gas through Egypt at competitive prices could be quite challenging.

\footnotetext{
${ }^{55}$ Reuters (2018). 'Cyprus-Egypt gas pipeline to cost $\$ 800 \mathrm{mln}-\$ 1$ bln”, 7 May. https://www.reuters.com/article/egypt-energycyprus/update-1-cyprus-egypt-gas-pipeline-to-cost-800-mln-1-bln-idUSL8N1SE353.

${ }^{56}$ Nicolò Sartori et al. (2016). 'Energy Resources and Regional Cooperation in the East Mediterranean', IAI Working Paper,

October. http://www.iai.it/en/pubblicazioni/energy-resources-and-regional-cooperation-east-mediterranean.

${ }^{57}$ Bloomberg (2018). 'Israel to Export Natural Gas to Egypt in \$15 Billion Deal', 19 February.

https://www.bloomberg.com/news/articles/2018-02-19/noble-delek-sign-15-billion-deal-to-export-israel-gas-to-egypt
} 

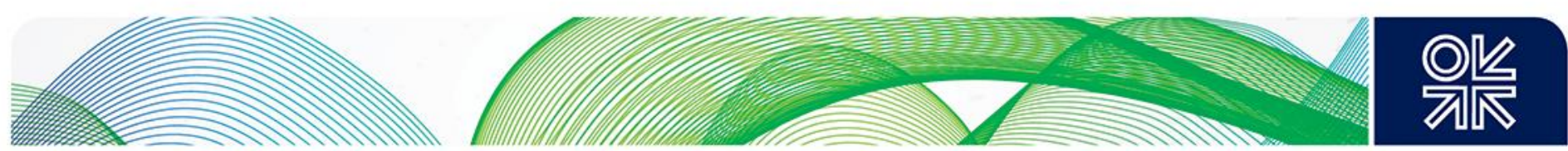

\section{Conclusions}

Egypt is undergoing a major transformation of its economy in general and its energy sector in particular. Due to the dominant position of natural gas in the country's energy scene, key changes are taking place in the natural gas subsector which significantly impact on other energy subsectors, especially power, as well as on other segments of Egypt's economy.

The quick answer to the question posed in this paper's title 'Egypt - a return to a balanced gas market?' could be: yes, but not for long. However, this short statement would not do justice to the considerable efforts deployed by all the relevant stakeholders in relaunching Egypt's hydrocarbon activities, bringing on-stream, in record time, several new gas supply projects and boosting indigenous production. It would also ignore the fact that the answer is based on current publicly available data and information on both the supply and demand sides.

Very shortly the Egyptian natural gas market will be balanced again, and gas exports may resume by the end of this decade or beginning of the next one. Meeting the needs of the domestic gas market has been one of the key objectives and priorities of the Egyptian government. This target is about to be achieved and a balanced market could possibly be sustained until at least the early 2020s, based on the above-mentioned assumptions. It should be noted that some of the past gas consumption could be considered as repressed or rationed demand. As more gas supplies become available, but at higher or much higher prices, how would this demand adjust to the continuous reform of domestic energy prices and a significant reduction of energy price subsidies?

Egypt's future natural gas demand profile will depend on a number of factors. In addition to the country's economic growth prospects, the key drivers of gas demand growth are future movement of domestic gas prices, especially for gas supplies to the power sector, and adequate availability of natural gas infrastructure capacity to meet existing and potential expansion of gas demand in new areas/regions. A lot of effort is focused on developing alternative energy sources of electricity generation, but it will take longer than ten years to diversify the energy mix and to reduce significantly the level of gas-fired generation and therefore Egypt's total gas demand. The review of gas demand by sector of use shows that natural gas demand in Egypt will continue to grow, but at a slower pace compared to the last two decades' growth rate.

There is a need to focus not only on the yet-to-find gas resources to develop additional gas supplies and balance the market over a longer period, but also to pay further attention to the country's energy demand side. Without the full implementation of consistent and integrated energy demand-side management measures, Egypt could be exposed again to a gas supply surplus/deficit cycle. One of the key driving factors of all these measures is the reform of the domestic energy pricing structure, specifically for gas and electricity prices.

A new domestic gas market law and its executive regulations were issued in August 2017 and February 2018, respectively. Although its full implementation and the liberalisation of the gas market will take a long time to achieve and the fact that a number of implementation questions remain to be clarified, this new gas law is definitely a very important step forward in the reform of Egypt's natural gas sector.

The Egyptian government has already initiated courageous energy price reform measures with some positive affects in terms of restrained demand by some energy-intensive sectors of the economy. The government has also stated repeatedly its commitments to implement further reforms. However, it will continue to face challenges with regard to the price subsidy and payment problems of the gas-topower chain. Fully addressing these issues will take some time, possibly beyond this paper's time horizon, as it involves a complex combination of sensitive social, economic and political factors.

The timing of the full resumption of Egyptian gas exports, the level of these exports and how long the exports will last, are crucial issues that are continuously raised within and outside Egypt. Based on current, publicly available supply and demand data and information, Egypt is unlikely to regain its past 

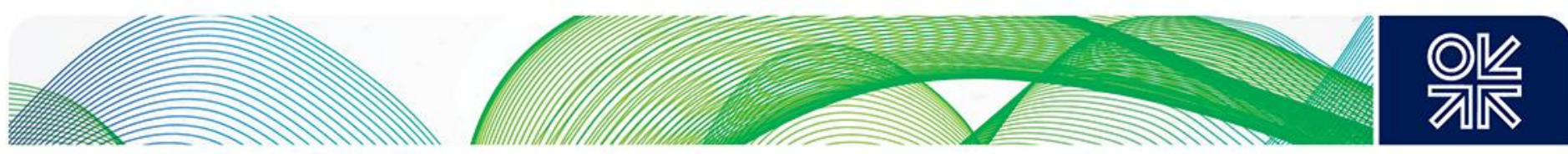

natural gas export position. The export window could last no more than a few years and export levels will decline quickly. However, there is the question of how the government will continue to monetise its gas resources, especially its additional gas supplies. Subject to its existing contractual gas export commitments, should it capture additional rent through further domestic gas monetisation (petrochemicals and industries) or mainly through exports or a combination of the two? Under a commercially viable energy pricing structure, such questions would be easier to address. But, it is difficult to justify the continuation of energy price subsidies to domestic gas monetisation projects, both economically and financially.

Egypt holds a central position in East Mediterranean gas developments. It has been promoting the option of becoming a natural gas export 'hub' to export gas from its own fields and also from neighbouring East Mediterranean gas producing sources. In order to achieve such a regional energy integration scheme, Egypt and its neighbours will have to surmount daunting obstacles related not only to geopolitical and territorial disputes, but also to address difficult commercial, contractual, and inter-governmental agreement constraints in the currently challenging international gas markets.

It is important to stress that the issue of gas market reform cannot be looked at in isolation from other energy subsectors, especially power. There is a critical need to reduce the heavy dependence on natural gas to generate electricity. As indicated above, Egypt's power sector is likely to continue to rely mainly on natural gas as a generating fuel for a long period of time. To shorten this period and reduce gas demand, it will have to intensify its efforts to develop a diversified mix of energy sources. This objective is supported by the government and international financial institutions through the launching of a series of renewable energy projects that will contribute to this diversification effort.

Finally, by the end of next decade, and most probably beyond 2030, Egypt's energy portfolio could be transformed with non-hydrocarbon sources of energy capturing an increasing share of the country's electricity generation mix. This could potentially release some additional supplies of natural gas for export, but by then Egypt will be facing international gas export markets that could be radically different from today's, especially in Europe under a decarbonization agenda. 